\title{
12 Die Personalisierung der Individualität im Medium von Rollen
}

\subsection{Die Individualisierung der Person und die Personalisierung des Individuums: Einleitung}

Wir erleben uns schon immer in einer Welt, die in dem Kontrast zwischen gegenstandsorientierter und latent selbstorientierter Aktivitätsrichtung aufscheint. Zudem unterscheiden wir anhand unseres eigenen Körperleibes zwischen Innen- und Außenwelt, wobei er als das Grenzverhältnis zwischen beiden Welten vorkommt, eben als der Unterschied und der Zusammenhang zwischen dem Leibsein und dem Körperhaben. Wenn man sich fragt, woher wir solche Differenzen (an unseren Aktivitätsrichtungen nach außen bzw. innen, gegenstands- respektive selbstorientiert) bilden können, kommt man auf das Strukturproblem der Mitwelt. Wir nehmen sie schon immer in Anspruch, während wir derartige Differenzierungen vornehmen. Insofern trägt uns die Mitwelt (siehe erster Teil des vorliegenden Buches).

Aber wenn man es nicht bei einem Spuk oder Gespenst von der Mitwelt belassen will, müssen wir, personale Lebewesen, doch selber sie auch bilden. Die Mitwelt wurde (im 11. Kap.) als das Schauspiel der soziokulturell elementaren, an den Eigennamen gebundenen Rolle fassbar, dank der sich jede Person von uns verdoppeln kann, was sich in der Kindesentwicklung am Umgang mit Puppen, Teddys etc. anschaulich zeigt. Unser Doppelgängertum ist vom Phänomen her offenbar, wenn wir uns den Zugang zum eigenen Körper vergegenwärtigen, dem wir als Leib - im Extremfall auf Gedeih und Verderb - ausgeliefert sind, während wir ihn als Körper zu beherrschen vermögen. Dieser unmittelbare Zugang lässt sich auch sprachlich zum Kategorischen Konjunktiv der Lebensführung entfalten, in der wir gemeinhin die Unvertretbarkeit und Einzigartigkeit unseres leiblichen Ichs mit der soziokulturellen Vertretbarkeit und Erwartbarkeit eines allgemein verkörperbaren Ichs auszugleichen versuchen. Im elften Kapitel wurde dieser Unterschied näher als das Schauspiel vorgestellt, das der Träger der persona, der in der Elementarrolle seines Eigennamens spielt, und der Rollenspieler, der mit dieser Rolle spielt, miteinander oder auch gegeneinander aufführen können.

Im vorigen Kapitel standen die Phänomene der Individualisierung der an den Eigennamen gebundenen Elementarrolle im Vordergrund, d. h. sie selbst wurde als gegeben angenommen. Wer in seiner Rolle spielt, erlernt deren Kompetenzen, sich auszudrücken, zu handeln und zu sprechen. Die Ambivalenz 
seiner eigenen Körper-Leib-Differenz wird durch diese soziokulturelle Verkörperung vereindeutigt, bestimmt und verendlicht. Zur Ausübung der Rolle gehört für die Interaktionspartner ein Spielraum und für den sie Aufführenden eine Verdopplung seiner Existenz in eine private und öffentliche. Während die Praktizierung der Rolle einem Dauertest im Blickkontakt mit anderen Bezugspersonen unterliegt, entsteht der Rollenspielerin ihr Individualisierungsproblem in drei elementaren Selbstbezüglichkeiten (kognitiv, praktisch und ästhetisch). Je nachdem, wie dieser Test ausgeht und wie jene Rückbezüge auf den eigenen Körperleib entstehen, spielt man nicht nur in, sondern auch mit der Rolle, womöglich gegen sie an. Die Aufführung der Rolle wird damit für andere mehrdeutig und für einen selbst mehrsinnig. Die Grenzen des Rollenspiels für einen selbst und beobachtbar für die anderen wurden an den Phänomenen des ungespielten Lachens und Weinens angeschaut, wenn nämlich das Rollenspiel leiblich gesehen zu mehrsinnig und körperlich betrachtet zu mehrdeutig wird, der Situation mithin widerspricht oder in ihr zu einem Sinnverlust im Ganzen führt.

Die Individualisierung der Rolle kann auf souveräne Weise anheben, etwa in einem dementsprechend lächelnden Umgang mit ihr, oder an den allzumenschlichen Charakter bedingter Süchte und Leidenschaften anschließen. Der individuelle Spielraum mit und in der Rolle potenziert sich nochmals - nach der Differenz privat-öffentlich - enorm in den Möglichkeiten, sie alltäglich und außeralltäglich zu praktizieren. Während sich bedingte Süchte so darstellen, als ob man in ihrem außeralltäglichen Genuss die Erfahrung ungespielten Weinens ins eigene Verhaltensspiel einholen kann, scheint der außeralltägliche Charakter bedingter Leidenschaften die Lachgrenze des eigenen Verhaltenskreises durch Selbststeigerung zu verschieben. Indessen kann aber die Bedingtheit der Süchte und Leidenschaften, sie nämlich aufs Außeralltägliche zu beschränken, verloren gehen und muss das Rollenspiel nicht zu einer Individualisierung durch Unterschreitung oder Überschreitung der Rolle führen. Man kann sich auch mit der Rolle bis ins Unbedingte hinein identifizieren oder, statt dieser Fremdautorisierung eben der Selbstautorisierung gegen sie zum Opfer fallen, sofern einem die eigene Sucht oder Leidenschaft ins Unbedingte entgleitet. Die Verkehrung dessen, was als eine außergewöhnliche Erweiterung des eigenen Verhaltensspieles begann, in einen neuen Alltag, der nichts anderes mehr als das Unbedingte praktizieren soll, transzendiert das ungespielte Weinen und das ungespielte Lachen. Was zwischen diesen Verhaltensgrenzen an Spielpotentialen lag, liegt sodann jenseits von ihnen und vermag sich damit ins Unmenschliche zu wenden.

Die Verkehrung der condition humaine, der Bedingtheit menschlicher Existenz im Ganzen, in das Potential zu unmenschlichem Verhalten beginnt in der 
Zerstörung des je eigenen Doppelgängertums, als ließe sich tierische Instinktsicherheit künstlich herstellen und als wäre sie der Maßstab. Die elementare Wirförmigkeit des eigenen Ichs, zwischen der leiblich unvertretbaren Individualität und der körperlich vertretbaren Personalität zu leben, gewährt alle nötigen Ambivalenzen, eindeutig und mehrdeutig spielen und dieses Spielen am Ungespielten des Lachens und Weinens begrenzen zu können. Das Spielspektrum der Phänomene zwischen solchem Lachen und Weinen zu durchlaufen erneuert das Potential, aus dem für einen selber Unbestimmten, Unbedingten und Unendlichen ins Bestimmen, Bedingen und Verendlichen des Lebensvollzuges zurückkommen zu können. Die Perspektivenwechsel bleiben innerhalb dieses Phänomenspektrums an die Positionswechsel des eigenen Körperleibes lebbar gebunden. Wer dieses Spektrum aber jenseitig überschreitet, respektiert sich nicht mehr als letztlich unausdrücklichen und unergründlichen Menschen, anerkennt sich selbst nicht als individuum ineffabile. Der Kategorische Konjunktiv des eigenen Lebens verschwindet so in dem Kategorischen Imperativ, das je eigene Unendliche, Unbedingte und Unbestimmte endgültig bedingen und bestimmen zu müssen. Wer sich selbst nicht mehr für noch bestimmbar und bedingbar hält, bringt die Wirform des eigenen Ichs zum Erlöschen. Wer sich Gewalt antut, kann anderen gegenüber gewalttätig werden. In der Gewalt beginnt das künstliche Sterben.

Im Unterschied zu diesem Phänomenenspektrum, das exemplarisch eine gelingende oder scheiternde Individualisierung der Person verdeutlichen sollte, geht es in dem folgenden Kapitel endlich um die Ausdifferenzierung der bislang als elementar unterstellten Rolle, eine persona zu spielen. Wir können fortan voraussetzen, dass es im Rollenspiel zur Ausbildung individueller Rückbezüge auf die eigene Körper-Leib-Differenz kommt, um uns nun einerseits mehr dem Selbstlauf der Interaktionen zu überlassen, ihrer Pluralität also Rechnung zu tragen, um aber andererseits auch wieder Rückschau darauf zu halten, welche soziokulturellen Formen der Personalisierung von Individuen deren Individualisierungsprozess eher fördern oder behindern. Anderenfalls hielten wir nicht an Plessners These vom Doppelgängertum der Angehörigen personaler Lebensformen fest. 


\subsection{Drei Rollenbegriffe: Das privat-öffentliche Doppelgängertum der Würde bricht die Individualisierung, Vergemeinschaftung oder Vergesellschaftung der Person}

Dass ein jeder „sich nur im Umweg über andre und anders als ein Jemand hat, gibt der menschlichen Existenz in Gruppen ihren institutionellen Charakter": Die Mitwelt begegnet nun als ,ein Geflecht aus Person und Sache, eine Welt des Wir, in der jeder zu jedem in der ersten, zweiten, dritten Person Rückbezüglichkeit und Gegenseitigkeit seiner Verhältnisse zu beachten hat“ (Plessner 1983e, 194). Die historisch gewachsene Mitwelt erscheint der in sie Hineingeborenen zunächst als das unmittelbar Selbstverständliche. Erst im Maße nachträglicher Besinnung auf Grund von Konfliktsituationen tritt die Mitwelt thematisch hervor. Das soziale Gefüge, der Außenhalt, von dem her wir uns exzentrisch erleben können, inkorporiert uns „als Jemanden mit Namen und Status“ (ebd., 196f.): Durch den Namen werden wir für uns selber wie für die anderen zu einem ansprechbaren Individuum, dessen Selbst am Namen nach außen wie nach innen Halt findet. Der Status betrifft „die weite Spannung des Rollenbegriffs“ zwischen einerseits dem ascribed status, also dem, „was einer durch Geburt und Umstände im sozialen Felde ist", und andererseits dem achieved status, also dem, „was er aus sich macht“ (ebd., 201).

„Elementare Rollenhaftigkeit“ nennt Plessner, so zur Erinnerung, den „fundamentalen Zug leibhafter Existenz, die eines Namens bedarf, woran sie zur Person wird“ (Plessner 1983e, 198). Unter der im Verhaltensspiel erlernbaren, die Personalität auszeichnenden dreifachen Positionalität war verstanden worden, sich selbst, also personal, von außerhalb seines eigenen Körperleibes, eben exzentrisch, als die Differenz zwischen unvertretbarem Leib, der uns einschließt, und vertretbarem Körper, der anderen Körpern gleicht, gegeben zu sein. Demgegenüber unterstellt die Rolle „als theatralischer Begriff“ bereits, „dass es einen Rollenträger gibt, der seine Existenz wechselt, um die Rolle zu spielen“ (ebd.). Damit wird das Spielelement freigesetzt, wobei jetzt aber nicht wie im 11. Kapitel die leiblichen Rückbezüge aufs Individuum im Vordergrund stehen, sondern die sozialen Selbstbezüge der Verkörperung für und über andere Personen. Das Spielelement gestattet „nun einer Person, eine andere zu sein. Sie tritt an ihre Stelle.“ Die im ersten Schritt erfasste „Konstitution der Person“ wird im zweiten Schritt verdoppelt zur Grunderfahrung des „Doppelgängerturns“, für das sich „das Bild von Rollenspieler und Maskenträger“ anbietet, und das in repräsentativen Zusammenhängen zu einer „gesellschaftlichpolitischen Kategorie“ (ebd., 199) wird. Während im 11. Kapitel die privat- 
öffentliche Verdoppelung als die Spannung zwischen (mindestens privatem) Individuum und (wenigstens öffentlicher) Person thematisiert wurde, geht es jetzt darum, diese Verdoppelung interaktiv als eine von Personen zu begreifen. Die sich durch die Differenz von Privatem und Öffentlichem konstituierende Doppelgängerin kann sich darin zugleich - ihrerseits mit dieser Differenz schauspielernd - in Interaktionen als verschiedene Personen aufführen.

Die dritte Bedeutung des Rollenbegriffs, die häufig in den Sozialwissenschaften unterstellt wird, kommt erst durch eine - nach dem repräsentativem Rollenspiel - erneute Formalisierung in modernen Gesellschaften auf. Das Doppelgängertum (in privater und öffentlicher Person) wird dann als eine reine Funktion verstanden, ohne noch an besondere Persönlichkeiten und ihr besonderes Verhalten gebunden zu sein: Indem die Leute, wie man sich darüber zu sprechen angewöhnt hat, ihren persönlichen Halt mehr mit einer „nebelhaften Privatexistenz" als mit ihrer Rolle verknüpfen und ihre Leistungen von der Rolle ablösen und auf eine gesellschaftliche Funktion übertragen, machen sie sich „selber zu Funktionären“ (Plessner 1983e, 202). Der moderne Mensch als Funktionär von ihm vor- oder übergeordneten Verhältnissen privatisiert seine Trägerschaft der Rolle und veröffentlicht seine Rollenfigur, bis es zur Entkopplung von Privatem und Öffentlichem kommt, die elementare Lebensrolle also zerreißt. Damit wird die Zuordnung zwischen privater Motivation und öffentlich verwertbarer Leistung kontingent gesetzt und lebensgeschichtlich verwischt. Der Job ist keine Berufung mehr, nicht einmal mehr ein Beruf (könnte man in Anspielung auf Max Weber 1992 sagen).

Die Geschichte der westlichen Moderne ist aber ein Streit darüber, inwiefern diese Ablösung der sozial funktionalen Leistungen von den Personen, die sie erbringen bzw. empfangen, inwiefern also die Ablösung, hinter der bereits eine Ablösung der Person von der Individualität der Persönlichkeit steht, schmerzlos, problemlos und grenzenlos sein kann. Während die Liberalismusformen dazu tendieren, diese Frage zu bejahen, weil sie die Gewinne aus dieser Affirmation für höher als die Verluste veranschlagen, tendieren die Komunitarismusformen wegen umgekehrter Bewertung dieser Bilanz zu ihrer Verneinung. ${ }^{1}$ Die

1 Statt Individualität, Personalität und Funktionalität vollständig voneinander zu entkoppeln, gibt es verschiedene Möglichkeiten ihres Zusammenhangs. Vgl. im Anschluss an Hegel und George Herbert Mead zu drei Formen der wechselseitigen Anerkennung von Personalität und Individualität, denen allerdings die naturphilosophische Fundierung fehlt, Honneth $1992 \mathrm{u}$. 1994. Selbst wenn man eine Anhängerin von J. Rawls liberaler Theorie der Gerechtigkeit ist, muss man diese inzwischen in historisch-kommunitäre Narrative einbetten, um sie noch als geschichtlich-wirklich vertreten zu können (Nussbaum 2014). Es genügt hier, auf die Kommunitarismusformen von M. Sandel, Ch. Taylor und M. Walzer zu verweisen, um einzusehen, dass 
Philosophische Anthropologie darf durch keine begrifflich-methodische Vorentscheidung dieses Problem eliminieren, sondern muss es für den anthropologischen Vergleich mit anderen Modernisierungsformen offenhalten.

Für die Philosophische Anthropologie ist der mittlere Rollenbegriff, die These vom Doppelgängertum, spezifisch und der springende Punkt. Diese These schließt elementare Rollenhaftigkeit ein, ohne Personalisierung mit soziokulturellem Dasein kurzzuschließen. Die moderne Funktionalisierung führt zur Entkopplung von Rollenträger und Rollenfigur. ${ }^{2}$ Aber diese Entkopplung fällt im anthropologischen Vergleich erst auf, wenn man sie mit dem Doppelgängertum kontrastiert. Erst die Verdoppelung der Person in eine private und in eine öffentliche Person führt in dasjenige Grenzverhältnis hinein, in welchem Personalisierung das soziokulturelle Dasein der Interaktionen ermöglicht und umgekehrt nach Interaktionen gefragt werden kann, die Personalisierung ermöglichen bzw. behindern oder gar verunmöglichen. Die persona eröffnet sowohl den Zugang zur Vergemeinschaftung oder Vergesellschaftung der Interaktionen als auch den Rückbezug zur Individualisierung der Personen, die interagieren. Als seine Möglichkeit gibt sich der Mensch sein Wesen erst

kraft der Verdoppelung in einer Rollenfigur, mit der er sich zu identifizieren versucht. Diese mögliche Identifikation eines jeden mit etwas, was keiner von sich aus ist, bewährt sich als die einzige Konstante in dem Grundverständnis von sozialer Rolle und menschlicher Natur. (Plessner 1983e, 204)

Auf diejenige Grenze von Interaktionen, die es ermöglicht, dass die sozial Handelnden gleichwohl noch ihren personal nötigen Positionswechsel ausführen können, zielte Plessner schon in seinem Buch Grenzen der Gemeinschaft von $1924 \mathrm{ab}$, wenngleich in teilweise anderer Terminologie: „Was aber ist der Sinn des Spieles, wenn nicht die Irrealisierung des natürlichen Menschen zur Träger-

man sich in jeder neuen Gegenwart auch erneut der Widerspruchslösung zwischen Liberalismus- und Kommunitarismusformen stellen muss, wenn man nicht den Kontakt zur geschichtlichen Wirklichkeit der Zukunft verlieren möchte.

2 Natürlich besteht die Gesellschaft nicht aus Menschen, sondern aus deren Interaktionen, insbesondere Kommunikationen. Für Luhmann war aber die selbstreferentielle Ablösung der funktionalen Sozialsysteme von den Personen und Individuen so weit fortgeschritten, dass er jeden semantischen Rückbezug der Funktionen auf Menschen als „alteuropäischen Vernunftglauben“ ablehnte. Dadurch übernehme die moderne Gesellschaft die Rolle Gottes, werde Hybris zum Normalfall: „Die moderne Gesellschaft ist, wie der Gott des Aristoteles, mit sich selber beschäftigt. Sie tut, wie der Gott der Christen, alles, was sie tut, um ihrer selbst willen“ Luhmann 1997, 1127. Vgl. dagegen zur kommunitaristischen Gesellschaftsauffassung, die durch liberale Formen erweitert werden könne, Hans Joas 1997. 
schaft irgendeiner Bedeutung, irgendeiner Rolle“ (Plessner 1981b, 94)? Er verstand in diesem leidenschaftlichen Plädoyer für Gesellschaft (im Unterschied zur Gemeinschaft) Würde (im Unterschied zur Ehre) als die minimale Idee der Harmonie von Aktivitätsrichtungen, die „das Ganze der Person, den Einklang ihres Inneren und Äußeren“ (ebd., 75) betrifft. ${ }^{3}$ Die Personalisierung muss nicht nur Interaktionen und deren Ablösbarkeit von den Personen im Lauf der Geschichte ermöglichen, sondern im sensomotorischen Rückbezug auf den Personenspieler auch dessen Individualisierung, was schwer $\mathrm{zu}$ erreichen ist und daher leicht um den Preis der Lächerlichkeit misslingt.

Wenn man sich fragt, welche Bedingungen Interaktionen zwischen Personen auf die elementarste Weise einhalten müssen, um mit der Individualisierung der Personen verträglich zu sein, ist man ganz schematisch auf Formfragen verwiesen. Solche Formen bewahren einerseits der Person den für ihre Individualisierung nötigen Spielraum und ermöglichen andererseits gegebenenfalls eine bis zur Funktionalisierung fortschreitende Formalisierung. Auf den ersten Blick könnte Plessners Antwort auf die Formfrage altmodisch anmuten: Zeremonie und Prestige, aber sobald man sich auf interkulturelle Interaktionen einlässt, ohne in diesen die Anderen einem Assimilationszwang an das je Eigene zu unterwerfen, wird einem sein Ausgangspunkt plausibel.

Zeremoniell nannte er dasjenige Schema von Interaktionen, welches das personal nötige Spiel zwischen Gesicht (Offenbarung seines Innenlebens im äußeren Ausdruck) und Maske (Verhüllung des Innenlebens durch Verallgemeinerung und Objektivierung für den Blick von außen) statisch ermöglicht. Die Frage der Wahrung des Gesichts, wie man sagt, ist nicht nur aus asiatischen Kulturen bekannt, sondern sofort auch in anderen Kulturen resonanzfähig (Goffman 1967, 12). Wenn im sozial-interaktiven Auftritt nicht auf minimale Weise die Würde der Person gesichert wird, ist die freiwillige Fortsetzung der Interaktion und (selbst nur funktional gesehen) Erbringung personaler Leistungen unwahrscheinlich. Die Minimalbedeutung der Interaktion, dass an sie angeschlossen werden kann, wodurch sie sozial relevant wird, entfiele dann. Unter Prestige verstand Plessner die personenbezogene Dynamik des Interaktionsschemas (Plessner 1981b, 75, 85-91). Dieser dynamische Aspekt kehrt später in dem oben zitierten Unterschied zwischen dem achieved status und dem ascribed status wieder. Der Grundgedanke einer Verdoppelung der Person durch ihre darstellerische Verkörperung in eine private und öffentliche war hingegen auch schon 1924 hervorgehoben worden:

3 Zur systematischen Problemgeschichte von Plessners Würdeverständnis siehe Haucke 2003. 
Der Mensch verallgemeinert und objektiviert sich durch eine Maske, hinter der er bis zu einem gewissen Grade unsichtbar wird, ohne doch völlig als Person zu verschwinden. Eine Zweiteilung entsteht zwischen Privatperson und Amtsperson, Amt hier noch in einem ganz umfassenden [...] Sinne genommen. (Ebd., 82f.)

Zeremonie und Prestige werden heutzutage leicht für altmodisch gehalten, was zivilisationsgeschichtlich auch stimmt. Daraus folgt aber gerade ihre Aktualität, sobald man sich ein interkulturelles Zusammentreffen zwischen Angehörigen einer westlichen und einer außerwestlichen Kultur vergegenwärtigt. Man kann nicht alle soziokulturell möglichen Interaktionspartner vorab in die Rolle des Du derjenigen Gemeinschaft hineinzwängen, der man selber wie selbstverständlich angehört und die man daher zentristisch für den Weltmaßstab hält, zumal die Du-Rolle heutzutage die übliche Werbetechnik globaler Konzerne darstellt, ihre Konsumenten in Mitarbeiter zu verwandeln. Auch jede Kindesentwicklung, insbesondere in der Jugendzeit, spricht erneut auf Zeremonien und Prestige der Fellows und der Angehörigen anderer Gangs an, nicht zuletzt in den über das Internet massenhaft verbreiteten Serien und games.

Man wird durch die viel beschworene Verabschiedung von Zeremonie und Prestige nicht das Problem einer elementaren Schematisierung und Dynamisierung von Personalität los. Wenn Rollenhaftigkeit die Fortsetzbarkeit der Interaktionen zu Gesellschaft und Geschichte hin und gleichzeitig die Individualität der Person ermöglicht, dann kann sie nur höchst formal ausfallen, dann muss also in ihr von den Inhalten der immer gerade hier und jetzt ausgeübten Tätigkeiten der Person und den Inhalten der Tätigkeiten ihrer möglichen Interaktionspartner andernorts und zu anderer Zeit abstrahiert werden können. Dieses anthropologische Problem der basalen Sicherung einer formalen Würde taucht in allen Frühkulturen im hohen Stellenwert der Riten auf, die sich in gewisser Weise - allen antiautoritären Idealen zum Trotz - in der Kinder- und Jugenderziehung wieder einstellen. Dieses Problem hat aber auch die neuere ethnologische und Verhaltensforschung gerade an noch nicht modernisierten Kulturen gezeigt, wodurch deutlich wird, dass es sich bei der Frage nach elementarer oder formaler Würde um keine moderne Erfindung handelt, sondern eher um eine moderne Verlusterfahrung, die mit der tendenziell grenzenlosen Funktionalisierung im Westen zusammenhängen könnte.

Eibl-Eibesfeldt unterscheidet im Anschluss an interkulturelle Vergleichsstudien drei „Superstrategien“, die als schematisch-dynamische Muster in längeren Interaktionsketten immer wieder auftauchen. So untersuchten Brown und Levinson

höfliche verbale Anfragen (Bitten) in Tamil (Südindien), Tzeltal (Mexiko) und Englisch mit zusätzlichen Sprachproben in Malagasy und Japanisch. Sie stellten übereinstimmend fest, 
dass kleine Bitten durch Betonung der Gruppenzugehörigkeit und/oder unter Berufung auf soziale Ähnlichkeit - also der Betonung einer Gemeinsamkeit - vorgetragen werden (Superstrategie der intimen Höflichkeit). Größere Bitten erfordern formelle Höflichkeit durch konventionelle indirekte Sprechakte und Entschuldigung (Superstrategie der formellen Höflichkeit). Bitten, die so groß sind, dass sie eventuell auch abgeschlagen werden können, trägt der Bittsteller indirekt, also verblümt vor (Superstrategie des indirekten Hinweises). Aber nicht nur die Größe der Bitte, auch der soziale Abstand der Interakteure bestimmt entscheidend mit, welche der drei Superstrategien gewählt wird. Und das zentrale Bedürfnis, um das es in allen Fällen geht, besteht darin, das Gesicht zu wahren. Keiner will sich etwas vergeben, niemand will sein öffentliches Selbstbild gefährden, aber auch das seines Ansprechpartners nicht. (Eibl-Eibesfeldt 1995, 693f.)

Plessners große Entdeckung, unser Doppelgängertum im Sinne des mittleren Rollenbegriffs, der Differenz zwischen privater und öffentlicher Existenz also, ermöglicht es der Philosophischen Anthropologie, der häufigen Verwechselung der Individualisierung der Person mit der Vergemeinschaftung oder Vergesellschaftung des Individuums aus dem Wege zu gehen. Habermas sprach zum Beispiel unglücklich von einer „Individuierung durch Vergesellschaftung“ (Habermas 1988, 189f.). Auch die Vergemeinschaftung oder Vergesellschaftung betrifft nicht das Individuum, sondern die Person in dem Medium ihrer Rollen, die sich dank ihrer Verdoppelung mindestens privat von dem öffentlichen Anspruch freihalten können muss. Die Individualisierung von Personalität überhaupt ist keine Frage bloßer Willkür oder subjektiver Gespreiztheit. Sie ist auch keine Verinnerlichung (Internalisierung, Interiorisation) des Sozialen oder der Kultur durch einen Trichter. Diese falschen Vorstellungen von der Individualisierung folgen aus der bewusstseinsphilosophischen Erwartung, das Menschenwesen als das Bewusstseinswesen ließe sich dressieren. Indem man Individualisierung ans Bewusstsein hängt, obgleich sie biotisch doch längst im genetischen Code angelegt ist und in jedem spontanen Handeln hervortritt, lässt sie sich als eine moderne Erfindung feiern und gleichzeitig als avantgardistische Bewusstseinsindustrie betreiben. Die Behauptung, der Westen habe die Individualität erfunden, ist lächerlich, wenn man sich die Zeugnisse anderer Achsenkulturen angesehen hat, zum Beispiel die hochindividualisierten Darstellungen von Offizieren in der Terrakotta-Armee des chinesischen Kaisers in Xian.

Individualisierung setzt vielmehr in allen Kulturen leibseitig an den sensomotorischen Rückbezügen der Rolle auf den eigenen Körperleib, etwa an eine Sucht oder Leidenschaft, an und hat mindestens privaten Spielraum. Sie kann auch sprachlich bis in die Antinomie der beiden Ichs im Kategorischen Konjunktiv hinein explizit gemacht werden, muss mindestens aber implizit in der leiblichen Unvertretbarkeit des Ichs und in der körperleiblichen Ganzheit des 
antinomischen Ich durch raumzeitliche Bewegungen behauptet (eben: positioniert) werden (siehe hier 11. Kap.). In der Differenz zwischen privater und öffentlicher Person kann jede Bewegungsrichtung nur gebrochen, also indirekt wirken. Ob Individualisierung, Vergemeinschaftung oder Vergesellschaftung, sie stellen Aspekte des Rollenmediums der Personalität dar, also der dreifachen Positionalität, dass Personen in Relationen zu anderen Personen Körper haben und Leib sind. Personen leben in dieser Differenz, indem sie zwischen ihrer öffentlich zugänglichen und ihrer privaten Existenz zu unterscheiden und beide zu integrieren bemüht sind. Individualisierung, Vergemeinschaftung oder Vergesellschaftung beziehen sich alle nur auf Personalität, die zumindest in allen Achsenkulturen in den gebildeten und Ober-Schichten bekannt und ausgelegt wird, also seit Jahrtausenden (Joas 2017, 5. Kap.).

Personalität im Sinne des mittleren Rollenbegriffes heißt, die Würde der Person dadurch zu wahren, dass ihr der Spielraum zwischen ihrer privaten und öffentlichen Existenz erhalten bleibt. In diesem Spielraum kann ich mich nicht nur (privatissimo) gegenüber mir als (öffentlicher) Person individualisieren, sondern mit mir selber als einer anderen Person interagieren. Gewiss hat die Pluralisierung des eigenen Ichs, die nun nicht mehr nur das leiblich individuelle und soziokulturell verkörperbare Ich meint, sondern in die Wirform des eigenen Ichs auch die Interaktion mit anderen Personen qua Schauspiel einbegreift, je persönliche Grenzen, die letztlich auf das ungespielte Lachen und Weinen zurückverweisen.

\subsection{Das persona-Spiel führt aus dem Dualismus zwischen Handeln und Verhalten heraus und in den Kommunikationszusammenhang zwischen Interaktion und Medium hinein}

Man könnte besser, als auf nackten Zugriffen auf das Individuum durch Gemeinschaft oder Gesellschaft zu bestehen, sagen, dass Personalität das Medium darstellt, dem gegenüber sich Menschen individualisieren, indem sie sich auf eine indirekte Weise vergemeinschaften und vergesellschaften, also auf verschiedene Weise interagieren können. Man darf dann nur nicht unter Medium ein Mittel des instrumentellen Handelns verstehen, das ein Bewusstsein vom Zweck der Handlung voraussetzt. Vielmehr schließt der Medienbegriff an den Begriff der Inter-Aktionen an, in dem gerade das thematisiert wird, was zwischen den Handlungen einerseits und dem Verhalten andererseits liegt. Der Medienbegriff hebt dann den semiotisch-pragmatischen Aspekt, also den Auf- 
führungscharakter der Interaktionen, hervor, wodurch sie Kommunikationen werden.

Es ist sehr wichtig, diese grundbegrifflich andere als gewöhnliche Weichenstellung der Philosophischen Anthropologie zu verstehen, auch für das Terrain der Sozial- und Kulturanthropologie. Plessner hat früh und überzeugend mit Buytendijk zusammen den Behaviorismus, d. h. die Versuche einer ausschliesslich physiologischen Kausalerklärung des äußerlich beobachtbaren Verhaltens durch dessen Konditionierung im Sinne bedingter Reflexe, kritisiert, weil sie dem Spielraum und der Spielzeit im Verhalten von Lebewesen nicht gerecht werden kann (siehe Plessner 1983a). Aber er hat diese Kritik geleistet, ohne umgekehrt in einer ausschließlich sprach-hermeneutisch, d. h. am Selbstverständnis der Akteure ansetzenden Handlungstheorie den Ausweg zu sehen. An die Stelle des alten Dualismus zwischen einerseits Handeln, das man nur sprach-hermeneutisch aus dem Selbstverständnis der Akteure verstehen könne, und andererseits dem Verhalten, das man nur von außen beobachten, beschreiben und kausal erklären könne, tritt in der Philosophischen Anthropologie die begriffliche Umstellung auf Interaktion und Medien. Ob Gemeinschaft oder Gesellschaft, sie werden als Arten des Inter-Agierens begriffen. Ob Geschichte oder Kultur und Technik, sie werden, wie wir noch sehen werden, als Medien verstanden. Diese Umstellung beginnt bereits innerhalb der Naturphilosophie, nach der Lebewesen dank ihrer Selbstorganisation in ihrer Umwelt den Spielraum haben, mit Medien zu interagieren (Plessner 1975, 103f., 334-341). Zudem lebt das phänomenologische Aufschließen selber davon, dass dank eines Mediums Phänomene sich kundtun können, eine bislang praktizierte Annahme, die wir jetzt konzeptionell einholen. Der Zusammenhang zwischen Interaktion und Medien befreit uns auch von dem (insbesondere durch Arnold Gehlen artikulierten) Denkzwang, die biologische Sicherheit instinktiven Verhaltens soziokulturell wiederherstellen zu müssen, nämlich durch die bewusste Rekonstruktion des Verhaltens im Handlungsaufbau und durch autoritär stabilisierte Institutionen. ${ }^{4}$ Stattdessen können wir Plessners konzeptionelle Umstellung auf Verhaltensspiele zwischen Lachen und Weinen für soziokulturelle Phänomene konturiert fortsetzen.

In dem Wort „Inter-Aktionen“ schwingen Aktionen mit, wodurch man an Handeln denkt, das im Unterschied zum Verhalten als intentional geleitet gilt. Dafür spricht auch das Präfix „Inter“ im Unterschied zu „in“ (lateinisch). Han-

\footnotetext{
4 Zum Gegensatz zwischen Plessners Philosophischer Anthropologie und Gehlens empirischer Anthropologie Wunsch 2018. Zur falschen Leugnung dieses Gegensatzes in den Arbeiten von Joachim Fischer siehe Krüger 2016d.
} 
deln ist zwar etwas, das im Äußeren sichtbar wird, aber gerade nicht im Verhalten aufgeht. Man unterstellt beim Handeln eine Sinnorientierung der Äußerung, die vom Akteur auf etwas in seiner Umwelt weist, der Außenrichtung des Körperleibes und seines nach außen gerichteten Bewusstseins folgend. Intentionalität kann auch eine spontane Sensibilität bedeuten, z. B. für die Umwelt, wie Jakob von Uexküll sagt, oder eine Orientierungsrichtung, wie Husserl meint, die vor der durch Zeichen artikulierten Bewusstheit liegt, oder eine Stimmung, wie es Heidegger und Bollnow nennen. Intentionalität kann auch, wie etwa Freud und an ihn Anschließende es tun, auf aktual Unbewusstes oder Unterbewusstes erweitert werden, das sich dann spontan in der Äußerung zeigt, etwa in Form von Versprechern, unbewusst gegenläufiger Mimik und Gestik, hysterischem Verhalten etc.

Man sieht, wie durch diese für unser Jahrhundert typischen Erweiterungen von Intentionalität über Bewusstheit hinausgehend, noch stärker im Kontrast zum Selbstbewusstsein, langsam der Handlungsbegriff diffus wird. Der Handlungsbegriff entgleitet $\mathrm{zu}$ Äußerungen einer Intentionalität, für die letztlich doch das Bewusstsein der Maßstab bleibt. Oder das Handeln wird zu einem von außen beobachtbaren Verhalten, dem intern kein klarer Sinn mehr zugeordnet werden kann. Deshalb ist einerseits die Lebensphilosophie auf den Begriff des Ausdruckes zurückgegangen, der Intentionalität im weitesten Sinne annimmt, nicht speziell und aktual Bewusstes oder gar Selbstbewusstes meint. Demnach sind Lebewesen solche Wesen, die sich ausdrücken. Und deshalb haben sich andererseits in den Beobachtungsmethoden zunächst einmal Verhaltensbegriffe durchgesetzt, die die Binnenhermeneutik des beobachtbaren Verhaltens ausklammerten, was nicht immer so reduktionistisch wie in Pawlows Theorie bedingter Reflexe oder Skinners Behaviorismus erfolgen musste. Umso näher lag und liegt angesichts dieser Grenzen des Handlungsbegriffes seither der Wechsel zu dem Begriff der Interaktion.

Der Begriff der Interaktion schließt nicht aus, dass es eine intentionale Binnenhermeneutik der am Interagieren Beteiligten gibt. Intentionalität kann bei Aktionen mitlaufen, aber sie muss nicht das „Inter“ der Aktionen betreffen, geschweige dieses Inter selbst ausmachen. Auf jeden Fall hat Interaktion aber Grenzen. Was „in“ ist, ist nicht „inter“. Inter ist wortwörtlich, was dazwischen oder unter ist, jedenfalls nicht innen ist. Aber es ist auch ein Dazwischen im Äußeren, das von dem Innen der Inter-Agierenden begrenzt wird. Die Grenze nach innen wird nicht ausgeschlossen, wie im Behavior, sondern als eben die Grenze von Äußerungen nach innen anerkannt. Nur muss es keine umkehrbar eindeutige Zuordnung zwischen dem Innen der Agierenden und dem Dazwischen ihrer Äußerungen geben. Der Sinn des Interaktionsbegriffes besteht gera- 
de darin, die Zuordnung zwischen dem Innen und dem Dazwischen der Agierenden im Spielen zu lockern, bis im Extremfall eine völlige Entkopplung zwischen Innen und Dazwischen eintritt, sich also der Verhaltensbegriff wieder einstellt. Das Inter der Interaktion ist auch nicht einfach das Äußere gegenüber dem Inneren der Interaktionspartner. Was den Interagierenden äußerlich ist, ist nur in den seltensten Fällen auch zwischen ihnen, noch seltener das Dazwischen ihrer Aktionen oder das, was den Aktionen der Beteiligten unterliegt, sie fundiert.

Was hat nun dieser bislang eingekreiste, vom Verhalten und vom Handeln abgesetzte Begriff der Interaktion mit Kommunikation zu tun? - Das philosophische Problem in den alltagssprachlichen Verwendungsweisen von „kommunizieren“ und bedeutungsverwandter Ausdrücke liegt in dem Präfix „Ko“ - bzw. „So“ - „Co“, in einer Art von Mit-Gemeinsamem, das mitläuft, aber von niemandem der an der Kommunikation Beteiligten privatistisch, also andere ausschließend, angeeignet werden kann (Krüger 1990a u. 1993). Dieses MitGemeinsame der Kommunikation begegnet uns im Interaktionsbegriff als das Dazwischen der Aktionen wieder. Insofern haben beide Begriffe eine Gemeinsamkeit, gehen sie problemlos ineinander über, ist Kommunikation Interaktion, und ist umgekehrt Interaktion Kommunikation. Beide Begriffe heben auf etwas $\mathrm{ab}$, das den Bewusstseinen der Beteiligten vorhergehen, neben diesen Bewusstseinen laufen und diese Bewusstseine auch übersteigen kann, ohne Intentionalität ausschließen zu müssen. Nur ist nicht sie, die Intentionalität, der Punkt, auf den es in erster Linie ankäme, und von dem her alles aufgeklärt werden könnte. Die Pointe zielt vielmehr auf das Dazwischen oder das Mit ab, das sich in kein Epiphänomen einer beteiligten Intentionalität auflösen lässt. Es ist nicht Folge, Konsequenz oder bloßes Mittel von Intentionalität. Auch was die semiotische Weite angeht, sprachliche und nicht-sprachliche Zeichenrepertoires, können sich der allgemeine Kommunikationsbegriff und der allgemeine Interaktionsbegriff vollständig überlappen. Beide treffen auf Lebewesen überhaupt zu und können über die Selbstreferenz der Sprache für Menschen spezifiziert werden, ohne dass das natürliche Kontinuum zwischen allen Lebewesen geleugnet werden müsste (siehe den Überblick über Handlungstheorien bei Joas 1992).

Indessen ermöglicht nun aber der semiotische Aspekt, der dem Kommunikationsbegriff eigen ist, einen anderen Vergleichspunkt, nämlich die Einführung des Medienproblems in unsere Erörterung. Kann man das Dazwischen der Interaktion, da es doch dem Mit-Gemeinsamen der Kommunikation zu entsprechen scheint, als Medium fassen? - Auch hier will ich vom umgangssprachlichen Gebrauch des Wortes Medium und seiner Wortgeschichte aus starten. 
Man versteht unter einem „Medium“ ein Mittel oder einen Mittler, wobei beides sowohl stofflich als auch personal gemeint sein kann. Seit dem lateinischen Ursprung wird jedenfalls darunter etwas in der Mitte Stehendes verstanden, das als Adjektiv medius heißt und in neutraler Form zu medium substantiviert worden ist, insofern es eben als Mittel oder Mittler taugt. Ein Medium kann etwas ablenken, brechen oder überbrücken, sei es als Stoff, Welle oder Person, etwa Versuchsperson oder spiritualistisch gedacht, wodurch etwas in Erscheinung tritt oder eine Verbindung hergestellt wird.

Aus dem Umstand, dass ein Medium ein Mittel sein kann, folgt nicht, dass wir den Ausdruck „Medium“ mit „Instrument“ oder „Werkzeug“ im weitesten Sinne gleichsetzen könnten. Selbst wenn ein Medium ganz unlebendig vorgestellt wird, nicht also als personenhafter Mittler, verbinden wir doch mit diesem Wort die Erwartung, dass es uns etwas sehen, hören, fassen lassen möge. Es ist dann eine Art Kontrastmittel, wie etwa die Röntgenstrahlen, die uns etwas sehen lassen, was ansonsten unsichtbar bliebe. Im Medium des Wassers sieht alles gebrochen aus. Im Medium der Luft wird alles gebremst. Die Mittelfunktion eines Mediums ist schon immer eine semiotische. Es geht primär nicht um andere Gebrauchs- oder Nutzenaspekte, sondern um ein Mittel, durch das sich etwas zeigt, wahrnehmbar wird. Selbst ein nur stoffliches oder im weiten Sinne materielles Medium hat einen lebendigen Bezug zu unseren Sinnen, dem Visuellen, dem Auditiven, dem Taktilen.

Es handelt sich hier um die Technik der Semiosis, der Zeichengebung, aber nicht in dem trivialen Sinne, dass ein Zeichen einen Träger braucht, wobei man dann den Träger wieder als Werkzeug oder Instrument ansehen könnte. Zwischen dem Bezeichneten und dem Bezeichnenden kann ja Arbitrarität herrschen, d. h. eine Willkür in der Zuordnung beider, wie bei den meisten sprachlichen Zeichen. Bei ihnen gibt es keinen inhärenten Zusammenhang zwischen Lauten, Buchstaben und sogar ganzen Worten einerseits und dem dadurch Bezeichneten, d. h. dem semantischen Inhalt oder der pragmatischen Konsequenz anderseits, es sei denn, man verwendete sie dichterisch, symbolisch, analogisierend oder magisch.

Ein Medium hat indessen etwas Dichtes, vielleicht sogar Dichterisches. Es ist nicht einfach arbiträr zu dem, was es ans Licht, zu Gehör oder zu fassen bringt. Es gibt einen viel stärkeren als nur zufällig konventionalisierten Zusammenhang zwischen dem Medium und dem, was es strahlen, hören, fühlen oder sonst wie erscheinen lässt. Der Effekt des Mediums und das Medium des Effekts sind sich keineswegs gleichgültig. Man kann sie nicht voneinander ablösen, wie man etwa Instrumente und deren Produkte voneinander ablösen kann. Der und der Effekt kommt durch kein anderes Medium zustande. Und das und das Medi- 
um zeitigt keinen anderen Effekt als den, der ihm zugehört. Man kann versuchen, zwischen Medien und ihren Effekten zu übersetzen, aber die Übersetzung wird immer unvollständig sein und einer gewissen Art von Interpretation, von Nachdichtung, bedürfen. Man denke an die Bemühungen, Romane zu verfilmen, Theaterstücke als Fernsehspiele zu übertragen, oder wortwörtlich Gedichte von Ezra Pound auf Deutsch zu bringen, um nicht noch Schwierigeres anzuführen, etwa Musik oder Gemälde in Worte zu fassen. Es gibt beides, das Medium und seine Effektart, auch nur gleichzeitig, in gleichzeitiger Aktion. Medium ist eine Art von Materialität, die Aktualität ermöglicht. Aus vielen möglichen Sinnzuweisungen wird eine bestimmte tätig realisiert, in Aktion versetzt, eben aktualisiert, tatsächlich gemacht.

Man kann nicht einzelne Sprachzeichen ein Medium nennen, wohl aber das Ganze der Sprache, das in actu verschieden proportioniert wird. Überhaupt scheint es beim Medium nicht einfach um eine Bezeichnungsfunktion zu gehen, die man sich instrumentell zu erfüllen denken kann. Die Mediatisierung, d. h. das Medium in Aktion, hat etwas von einer Zeigehandlung, Deixis, während der die semiotischen Elemente nicht voneinander abgekoppelt werden können. Ein Medium ist eine Kopplung in Aktion, eben die Ermöglichung einer Verbindung, die es anders überhaupt nicht gäbe. Dies ist übrigens der Grund, warum die phänomenologische Philosophie im Gefolge Husserls von der Fundierung durch Medien spricht, die an die Stelle der transzendentalen Analyse von Ermöglichungsbedingungen bei Kant tritt. Schon Hegel meinte, wenn er gegen Kant von Vermittlung sprach, die Mit-Teilung zwischen etwas Substantiellem und etwas Subjektivem, zwischen etwas Lebendigem und etwas Reflexivem. Hölderlin hatte das Vermittlungspotential von Geist metaphorisch den Äther genannt (siehe Krüger 2014).

Dies leitet schon über zu der zweiten Bedeutungsdimension von Medium, das nun nicht mehr nur als Kontrast-Mittel im semiotischen Sinne der Ermöglichung des Aufzeigens, sondern als Mittler firmiert, der über noch mehr Eigensinn oder Brechungskraft als das Mittel-Medium verfügt, weil er als personenhaft gilt. Die primär semiotische Zeigefunktion bleibt auch jetzt noch erhalten, wenn unter Medium ein personenhafter Mittler verstanden wird, sei es, dass wir durch diese Person mit Geistern in Kontakt kommen sollen, sei es, dass wir sie als Versuchsperson im psychologischen Labor oder in einer magischen Aufführung erleben wollen, sei es, dass wir alltagssprachlich diese Person als Mittler zu Mitmenschen einsetzen möchten oder wie ein Regisseur einen Schauspieler, oder wie ein Dirigent ein Orchester als Medium einsetzen möchten, um etwas vorführen, aufführen, zeigen, sichtbar, hörbar, fühlbar machen zu können. So oder so soll das Medium im Sinne einer personenhaften Vermittlung eine Per- 
formance, eine Vorführung oder Aufführung von etwas ermöglichen. Es geht nicht um internalisierte Kompetenzen, die im Handeln geäußert werden, sondern um die Vorführung, wie im Äußeren zwischen allen wahrnehmbar, für alle beobachtbar dank dem Medium durch Kopplung etwas Neues ermöglicht wird. Gleichwohl gilt die Person, die als Medium fungiert, nur in dieser ihrer medialen Eigenschaft, d. h. als semiotische Ermöglichung vom Aufzeigen einer Verbindung, vom Wahrnehmbarwerden einer lebendigen Kopplung zwischen Person und Sinn.

Man könnte sagen, dass ein Medium dasjenige im Äußeren sichtbar, hörbar, fassbar werden lässt, was man sich ansonsten nur erschließen kann. Zwischen Innen, den intentionalen Zuständen, und Außen, dem Ausdrucksverhalten eines Individuums, muss es hin- und hergehen. Aber wir kommen da nicht hinein, jedenfalls nicht, ohne das Individuum zu zerstören. Wir können seine Wechsel zwischen innerer und äußerer Aktivität nicht wahrnehmen, sondern nur erschließen aus seinem - möglicherweise falschen oder gefälschten - Ausdrucksverhalten. Ein personenhaftes Medium nun hat die Funktion, etwas ansonsten Inneres im Äußeren sichtbar werden zu lassen. Statt uns direkt im Innern des Anderen zu verhakeln, dort den Analytiker zu spielen, statt uns dort zu verlieren, taktlos in die Tiefe zu bohren, sich dem Gewissen aufzudrängen, lassen wir uns dieses vermeintlich Innere durch das Medium einer dritten Person als Kontrast entstehen, aufzeigen, wahrnehmbar machen. Durch das Medium geht man also den indirekten Weg. Das vermutete innere Zentrum soll dank des Mediums in der Mitte des Äußeren aufleuchten, eine Art von Hirn- und Herzröntgen, aktueller gesprochen ein MRT oder CT beider Organe, wenn man so will. Das macht das Phänomenale am Medium aus. Es ermöglicht den Sinnen ein Phänomen, eine Art von Gestaltsprung, den es so bisher noch nicht gab. Man stelle sich den Einsatz von Ultraschall und Infrarotkameras vor oder denke an Tänze, an die ersten Fotografien, Stumm- und Tonfilme (seinerzeit eine wirkliche Revolution der Wahrnehmung), an die Geschichte der modernen Malerei und Musik zwischen Impressionismus und Expressionismus.

Dies bedeutet aber auch, dass wir mit dem Begriff des Mediums, ob als semiotisch-deiktisches Mittel oder als personenhafter Mittler für Performances, immer die dritte Person verbinden, die einen semiotischen Effekt aufzuführen oder vorzuführen ermöglicht. Eine Person kann natürlich ein einzigartiges Ich und ein unvertretbares Du sein. Aber gerade diese Eigenschaften sind nicht gefragt, wenn diese Person als Medium fungiert, das nicht selber unvertretbar und einzigartig sein soll, sondern umgekehrt diejenige dritte Person sein mag, die Unvertretbares oder Einzigartiges im Kontrast sichtbar werden lässt. Der Prototyp des Mediums ist semiotisches Kontrastmittel, des Mediums als Mittel 
also, sind Wasser, Luft, Sonne, Erde, wenn man an Mythen und kulturgeschichtliche Anfänge denkt. Nicht nur Homer, die ganze griechisch-antike Philosophie ist voll davon. Der Prototyp des personenhaften Mediums, des Mittlers also, ist der Schauspieler, und zwar genauer gesagt: seine Maske als der Kontrast, der das seelisch Innere als Äußeres hervortreten lässt. Die persona ist, etymologisch betrachtet, zunächst die Maske, ehe sie dann auch als die Verkörperung vergleichbarer Rechtstitel zählt.

Genau hier, in der Maske der dritten Person, setzt die Philosophische Anthropologie an. Die Maske der dritten Person fungiert als die exzentrische Mitte, also als die Mitte außerhalb des eigenen Leibkörpers, die Mitte im Äußeren zwischen den Individuen, von der her als Kontrast wir uns wahrnehmbar werden. Von der dritten Person als dem Medium her lernen wir unser intentionales Erleben erleben, aber nun dank des Mediums im Äußeren. Damit ist der Zirkel christlicher Reflexion, wie er seit Thomas von Aquino bis in die Existenzphilosophie unseres Jahrhunderts vorangetrieben worden ist, immer tiefer in die eigene Seele hinabsteigen zu müssen, durchbrochen zugunsten der Mit-Welt, nun der persona als medium.

Nach dem bisher Gesagten scheint die folgende Zusammenfassung sinnvoll zu sein: Das Dazwischen der Interaktion und das Mit- bzw. Ko-Gemeinsame der Kommunikation lassen sich wohl als ein Medium qualifizieren. Während der Interaktionsbegriff auf das Dazwischen im Äußeren der Akteure und damit auf das Dazwischen zwischen Handeln und Verhalten verweist, thematisiert der Kommunikationsbegriff dieses Dazwischen semiotisch. Das Ko- wird als die Koordinierung durch die Aktualisierung von Zeichenpotentialen verstanden. Der Medienbegriff qualifiziert nun diesen Koordinierungseffekt als eine aktuale Semiosis in der Form einer Deixis. Die Bezeichnungen, die Zuordnungen zwischen Bezeichnetem und Bezeichnendem, werden nicht einfach vorausgesetzt, sondern vorgeführt wie ein Phänomen. Ein Medium ermöglicht die Vorführung semiotischer Unterscheidungen, indem es als das Kontrastmittel (Neutrum) oder als der Mittler/die Mittlerin (personenhaft) der dritten Person fungiert. Der Unterscheidung zwischen sprachlicher und nichtsprachlicher Kommunikation entspricht jetzt auf Seiten des Medienbegriffs der Unterschied zwischen ganzer Sprache (nicht ihren Elementen) und der Maske als dem Medium der Verkörperung von Leiblichem. Diese, die Sprache und die Maske der dritten Person, sind anthropologisch gesehen die beiden Grundmedien, die als Kontrast alles andere erst hervortreten, sehen, hören, fassen, für wahr nehmen lassen, darunter insbesondere das Wechselbad zwischen der kulturellen Entfremdung der Nachwachsenden und der Erzählung einer eigenen Geschichte. Sprache und Masken können einander davonlaufen, so dass die spezifisch geistigen Wirkungspoten- 
tiale nicht mehr den Körperleibbewegungen entsprechen. Die Perspektiven und Positionen werden dann gleichsam entkoppelt voneinander. Oder die Körperleib-Positionen und die sprachlich möglichen Perspektivennahmen werden wieder in dem Sinn einer Geschichte zusammengeführt, sozusagen aneinander gekoppelt. Alle weiteren Differenzierungen von Medien müssen hier ansetzen, falls denn überhaupt ein philosophisch gehaltvoller Medienbegriff für soziokulturelle Phänomenen Verwendung finden soll, also nicht nur eine Analogie zum Instrument oder Werkzeug (näher in Krüger 2006b).

\subsection{Personalität als das Medium gemeinschaftlicher Interaktionen: das Familien- und Sachmodell der Gemeinschaft und die Grenzen der Vergemeinschaftung von Personen}

Wir können nun an ausgewählten Phänomenen derjenigen Differenzierung nachgehen, die das elementare Doppelgängertum des Unterschiedes zwischen privater und öffentlicher Person in soziokultureller Hinsicht erfährt. Der privaten Person können die leiblichen Rückbezüge des unvertretbaren Ichs vorbehalten bleiben, während die öffentliche Person als Interaktionsmedium fungieren kann. Dabei erscheinen die gemeinschaftlichen Interaktionen dank ihrer Wertorientierung wie Antworten auf das Problem, die Kontingenzen der persönlichen Lebensführung überhaupt durch eine Bindung gestalten zu können. Eine Gemeinschaftsbindung ermöglicht der Doppelgängerin, sich endlich bestimmbar und bedingbar zu werden, wodurch diese Bindung oft wie eine Verlängerung der privaten Existenz erscheint. Gleichwohl ist sie dies nicht, wie es spätestens Pubertierenden klar wird. Die gemeinschaftlichen Interaktionen nehmen zwischen Personen bereits die öffentliche Existenz der Personen in Anspruch, was oft erst in einer - gemessen an der ursprünglich gemeinsamen Werteorientierung - schmerzlichen Ablösung hervortritt. Demgegenüber erscheinen die gesellschaftlichen Interaktionen von vornherein als eine Ausgestaltung der Ambivalenzen, die dem öffentlichen Leben eigen sind, und die in das der Person Unbestimmte, Unbedingte und Unendliche führen können. Gesellschaftliche Interaktionen bedürfen eines Äquivalentes für die ihnen fehlende gemeinschaftliche Wertbindung, um mit dem Doppelgängertum verträglich bleiben zu können (worauf ich in 12.5. eingehen werde).

Die öffentliche Person ist die soziokulturelle Ausgestaltung der exzentrischen Positionalität in Form einer bestimmten soziokulturellen Position. Von dieser her kann der Rollenspieler die Differenz zwischen seinem Leibsein und 
Körperhaben verschränken. Die soziokulturelle Positionalität wird über Interaktionen mit Bezugspersonen der zweiten (Du) und dritten Person (Er/Sie/Es) Singularis erlernt, bis sie in der Form der ersten Person Pluralis, in der Perspektive eines Wir, als soziokulturelle Mitwelt geteilt werden kann. Diese Mitwelt wird vom Ihr der zweiten Person Pluralis, die eine andere Mitwelt teilt, unterscheidbar und in der Perspektive der dritten Person Pluralis (Sie) mit anderen Mitwelten vergleichbar. Während die Interaktion mit einem Du die motivierende Identifikation vom Rollenträger auf die Rollenfigur übertragen kann, werden in der dritten Person Singularis die Träger vor der Figur austauschbar und entsteht eine Vergleichsnot möglicher Träger für die betreffende Figur. Die WirPerspektive umgrenzt die „wertnahen“ Interaktionsarten, die Plessner (in Variation auf Ferdinand Tönnies' berühmte Unterscheidung zwischen Gemeinschaft und Gesellschaft: Tönnies 1979) unter dem Begriff der Gemeinschaft zusammenfasst. Dies bedeutet zunächst einmal nur, dass die sozial Handelnden diejenigen Werte teilen, nach denen sie ihre Interaktionen bewerten, insofern also einer Wir-Perspektive angehören.

Die motivationale Nähe der Werte zu den Interaktoren kann sich eher affektiv gestalten, d.h. nach dem Modell der im weiten Sinne familiären „Liebe“ (nicht speziell nach dem Muster der im 11. Kapitel erwähnten Leidenschaft) und deren symbolischer Übertragung. Man gewinnt hier den weiten Fächer von Verwandtschaftsbeziehungen (nach Geschlechter-, Generationen- und Lebensalter-Rollen), der insbesondere von der französischen strukturalen Anthropologie entfaltet worden ist, und der symbolischen Übertragbarkeit von Familienähnlichkeiten, auf die der späte Wittgenstein in seiner Beschreibung von Sprachspielen angespielt haben könnte. Seit Goethe spricht man auch von Wahlverwandtschaften.

Oder die motivationale Nähe der Werte stellt sich eher objektiv dar, d. h. nach der Art einer überhaupt rationalen Lösungsform für Sachprobleme, wie sie sich außerhalb der affektiven Bindungen an personale Raumzeiten darstellen lassen, z. B. in wirtschaftlichen Unternehmungen oder solchen der Bildung von scientific communities. Im ersten Fall der Familiarität oder der Familienähnlichkeit wird die Gemeinschaftsbildung eher an das personale Problem, Leib zu sein, diesen ausdrücken und anderes rezentrisch verleiblichen können zu müssen, angeschlossen. Der zweite Fall der Lösung sachlicher Aufgaben setzt eher bei dem personalen Problem an, einen Körper haben, ihn exzentrisch ausrichten und anderes verkörpern können zu müssen.

Im ersten Fall spricht Plessner vom Typus der „Existenzgemeinschaft“: Sie braucht der Affektwerte willen eine „Personmitte“ und tendiert insofern unter ihren Teilnehmern zur Hierarchie bezüglich dieser Person. Zeithistorsch nannte 
man solche Existenzgemeinschaften in den 1920er Jahren auch verengend Blutsverwandschaften, was auch metaphorisch gemeint sein konnte, dann aber von den Nationalsozialisten wortwörtlich verstanden werden sollte. Den zweiten Fall kann man den einer „Sachgemeinschaft“ (wie z. B. der Wissenschaft oder einer politischen oder wirtschaftlichen Sache) nennen, die den rationalen Werten entsprechend eine exzentrische „Sachmitte“ (idealiter von einem Nirgendwo/Nirgendwann her) braucht. Insofern tendiert sie langfristig zur „Gleichberechtigung“ ihrer Gemeinschaftsmitglieder vor der Sachlösung (siehe Plessner 1981b, 45-52).

Alle Interaktionen, die sich durch motivationale Wertnähe auszeichnen, sei diese eher existentiell zentrischer oder mehr rational exzentrischer Art, bilden eine gemeinschaftlich geteilte „Vertrautheitssphäre“, von der sich die „Nichtvertrautheitssphäre“ der „Gesellschaft“ unterscheidet. „Gemeinschaft ohne diese Grenze ist keine Gemeinschaft mehr“ (ebd., 56). Plessner hat erkannt, dass diese Grenze der Gemeinschaft, die ihr durch die gesellschaftliche Öffentlichkeit gezogen wird, mit der individuellen Grenze von Gemeinschaftlichkeit korrespondiert. In der Konfrontation der beiden Ideale des Gemeinschaftsethos, der Unendlichkeit der Liebe des Herzens und der Unendlichkeit des Vernunftglaubens an die geistige Sachbestimmung, „zeigen sich die Wesensgrenzen, die jeder Panarchie der Gemeinschaft hindernd im Wege sind: die Unaufhebbarkeit der Öffentlichkeit und die Unvergleichlichkeit von Leben und Geist“ (ebd., 55). Zur ersten Grenze der Unaufhebbarkeit von Öffentlichkeit:

Öffentlichkeit beginnt da, wo Liebe und blutsmäßige Verbundenheit aufhören. Sie ist der Inbegriff von Möglichkeitsbeziehungen zwischen einer unbestimmten Zahl und Art von Personen als ewig unausschreitbarer, offener Horizont, der eine Gemeinschaft umgibt. Sie ist gerade in dieser Negativität eine sozialformende Macht ersten Ranges. (Ebd.)

Und zur zweiten Grenze der Unvergleichlichkeit von Leben und Geist:

Das Leben ist kurz, schnell, beengt, und für die Wurfbahn, in der es sich von Geburt an befindet, sind wir nicht verantwortlich. Von Anfang an ist unserer Freiheit vom Schicksal ein höchst begrenzter Spielraum gelassen. Hier gilt es sich zu bewähren, was aber mit Argumenten nur zu einem sehr geringen Teil geschehen kann und geschehen darf. Von einer Mitte aus muss freilich alles geordnet sein, von der Wesensmitte der ganzen Person, nicht von einer Schicht ihrer Existenz [...]. (Ebd.)

Beide Gemeinschaftsgrenzen, die zum Individuum und die zur Gesellschaft als Öffentlichkeit hin, führen aus der Transparenz, Eindeutigkeit und Bestimmtheit heraus, die in einer Sphäre vertrauter Interaktionen dank des Werterepertoires und der Wertepriorität einer Gemeinschaft möglich sind. Sie führen, vom Standpunkt einer jeden schon immer bestimmten Gemeinschaft, hinaus in In- 
transparenz, in Ambivalenz bis in unüberschaubare Polyvalenz, in eine Unbestimmtheit als der Ermöglichung von Bestimmung (Bestimmbarkeit) hinein, damit aber auch in die Gefahr der Unbestimmbarkeit. In der Konsequenz gelangt man also auf beiden Grenzen der Gemeinschaft zur Unergründlichkeit des Menschen zurück, zum homo absconditus also, jetzt aber einmal in seiner Unerschöpflichkeit innerpersonaler Positions- und Perspektivenwechsel als individuum ineffabile genommen, und andererseits in der Unerschöpflichkeit interpersonaler Positions- und Perspektivenwechsel zwischen dem Wertegefüge nach unverbundenen Menschen, also als gesellschaftliche Öffentlichkeit verstanden.

Beginnen wir mit der Grenze, die sich aus den intrapersonalen (innerpersonalen) Aktivitätsrichtungen zur Individualisierung hin ergibt. Die Personalisierung dank der Verkörperung einer soziokulturellen Rolle, mit der man sich identifiziert, wird zwei- und mehrdeutig. Wie ist dies zu verstehen? - Die Ambivalenz der Individualisierung besteht darin, dass die Individualität einerseits der Wir-Perspektive als eines Verhaltenszentrums außerhalb ihres Körperleibes bedarf, um überhaupt in eine Selbstbeziehung gelangen zu können. Andererseits lernt man, indem die Individualität zu sich selbst kommt, sich zugleich von der gemeinschaftlich geteilten Wir-Perspektive zu unterscheiden. Man erfährt sich in der Konsequenz des Maßstabes und am Maßstab der Gemeinschaft als unvertretbar und einzigartig. Es ist diese Zweideutigkeit der Individualisierung, die dem Bestimmungsversuch der Gemeinschaft, die personale Perspektive in der Wir-Perspektive aufgehen zu lassen, zuwiderläuft. Würde der innerpersonale Positionswechsel auf die Wir-Perspektive eingeschränkt, entstünde ein im Sinne der Gemeinschaftswerte durch und durch ,authentischer“ und „transparenter“, „eindeutig festgestellter“ und „,bestimmter“, also eine Art gläserner Mensch. Der Vergemeinschaftung der Person entspricht zwar die personale Tendenz, die Realität exzentrisch bestimmen und sich als anerkennenswert zeigen und offenbaren können zu müssen. Aber ihr widerspricht die für die Balancegewinnung des individuierten Selbstes nicht minder wichtige Gegentendenz, frei von der Anpassung an gemeinsam geteilte Werte Illusionen imaginieren und sein Innenleben gegen außen verhüllen können $\mathrm{zu}$ müssen, was eine Schamgrenze auch gegenüber der Gemeinschaft erfordert (siehe Plessner 1981b, 60, 66-75).

Der Vergemeinschaftung der Person ist die Grenze der Individualisierung der Person gesetzt, nicht nur, weil eine Person ihr Verhaltenszentrum verschieden exzentrieren und damit auch verschieden rezentrieren kann. Die Person kann sich überhaupt auf ihre einmalige leibhafte Existenz rückbeziehen, was man in unserer aristotelisch-christlichen Tradition die Entdeckung ihrer Seele (anima) nennt, im Unterschied zu ihren Verkörperungen, in denen sie sich ver- 
tretbar, austauschbar und ersetzbar wird. Was in dieser Kulturtradition den Menschen ,wirklich erst individualisiert, von innen heraus unteilbar und einzigartig macht, ist das Bewusstsein vom Besitz einer Seele, das Leben im Zentrum einer empfindenden, wollenden, denkenden, der Umwelt und dem eigenen Leibe gegenüber eigenwilligen, an Tiefe und innerer Eigenschaftsfülle unvergleichlichen Innerlichkeit“ (ebd., 61f.).

Im Prisma der Sprachpragmatik der Personalpronomina als unserem Kommunikationsmedium, in dem wir Perspektiven verschränken, ist die Individualisierung wie folgt $\mathrm{zu}$ fassen:

Die Position des Menschen lässt sich durch Personalpronomina deklinieren, die [...] ein doppeltes Verständnis des Wortes Ich möglich machen. Ich kann mich zu anderen in ein konstantes Gegenüber bringen, in dem mir eine ausgezeichnete Stelle reserviert bleibt, die eben nur durch mich hic et nunc ausgefüllt wird. Insofern sind ,Ich' und ,Hier‘ äquivalent. ,Ich“ bezeichnet den Ort, von dem meine Impulse ausgehen und auf den hin alle Perspektiven konvergieren. Dieser abstrakte Tatbestand kommt dem Menschen [...] konkret aber durch die eigene leibhafte Existenz zum Bewusstsein [...]. (Plessner 1983b, 338)

Setzt man psychogenetisch die Einbettung in ein intersubjektives Milieu voraus, begegnet die

ausgezeichnete Position des eigenen Ichs im doppelten Sinn der Stellen, die Ich hier ausfüllt (d. h. als eine Leerstelle, die auch ein anderer ausfüllen kann [...]), und in einer Binnendimension [...], welche ich einfach bin und habe als Rückzugsmöglichkeit in mich. (ebd., 339)

Demnach artikuliert sich Einzigartigkeit nur „vor einem Hintergrund, der sie nicht kennt. Individuelle und generelle Subjektivität, d. h. Intersubjektivität, implizieren einander. Als Individuum unersetzbar, steht jeder Mensch in seiner möglichen Ersetzbarkeit. Er könnte, aber er kann nicht“ (ebd., 340).

Die „strukturelle Antinomie, Individuum nur in dem Maß des Eingeständnisses seiner generellen Ersetzbarkeit durch einen anderen zu sein“, ermöglicht, mit Kant gesprochen, beide Tendenzen, die zur Geselligkeit und die zur Ungeselligkeit, die den Ausgleich zu ungeselliger Geselligkeit herausfordern (ebd., 342). Das Individuum hat sich auf dem Wege über andere und anderes, insofern aber auch auf eine vertretbare und ersetzbare Weise. Und es ist unvertretbar und unersetzbar im Unterschied zu diesem Weg seiner Vermittlungen durch andere und anderes. Die Affekt- oder Sachwerte einer bestimmten Gemeinschaft geben ein vertrautes Maß für Vertretbarkeit und Ersetzbarkeit an, das von Gemeinschaft zu Gemeinschaft ein anderes ist. Die inhaltliche Fülle an Interpretationen, was vertretbar/unvertretbar respektive ersetzbar/unersetzbar bedeuten, wird durch die strukturelle „Antinomie zwischen Ichsubjekt und 
Intersubjektivität, am puren Faktum: Wo ich bin und stehe, kann (könnte) jeder stehen“ (ebd., 346), historisch in Gang gehalten. Sie wird nicht nur im Indikativ realisiert, sondern auch im Konjunktiv irrealisiert. Und in ihr werden nicht nur Perspektiven sprachlich verschränkt, was das Übersetzungsproblem zwischen Sprachen aufwirft, sondern auch Positionswechsel an der Grenze zum Nichtsprachlichen zum Ausdruck gebracht (ebd., 347ff.).

$\mathrm{Ob}$ seelen-phänomenologisch auf die Anschauung der Positionen oder sprachpragmatisch auf die Besonderheit der Ichperspektive bezogen, die Feststellung der Individualposition und -perspektive auf eine bestimmte Gemeinschaftsperspektive stellt sich als problematisch heraus: Insofern nämlich, als die Benamung und Statuierung der Person, die also für die Betreffende passive Inkorporierung in ein Gemeinwesen, durch die Identifikation mit Gemeinschaftsrollen hindurch die Eigendynamik der doppeldeutigen Ich-Position erfährt, bis sich die Individualität von sich selbst, der bloßen Personalität, abheben und aktiv davon unterscheiden kann. Der verliehene Name und der mitgegebene Status werden zum Ausdrucks- und Handlungspotential des Ich selbst im Wechsel der personal möglichen Positionen und Perspektiven.

Die Philosophische Anthropologie zeigt also nicht nur die Notwendigkeit der Vergemeinschaftung von Personen anhand der - die Aktivitätsrichtungen des Körperleibes motivierenden - Affekt- und Sachwerte auf, als das Zuhause der Personen, das ihnen vertraut ist und sie mindestens zunächst motiviert. Die Philosophische Anthropologie ermöglicht auch umgekehrt diese Rückfrage: Welche Interaktionsformen begünstigen oder behindern die Individualisierung von Personen? - Diese Grenzfrage liegt einerseits im Hinblick auf die psychopathogenen Folgen der Feststellung einer Person durch eine und ausschließlich eine Gemeinschaftsperspektive nahe, andererseits hinsichtlich der konfliktuären Konsequenzen, die solche Feststellungen in der betreffenden Gemeinschaft selber zeitigen können. Der Gemeinschaft werden durch die genannte Feststellung von Personen alle personalen Leistungen entzogen, die durch die innerpersonalen Positions- und Perspektivenwechsel ermöglicht würden. Was die elementare Schematisierung von Würde in den wertbestimmten Interaktionen angeht, so entsteht in der Evaluierung der Personen eine Tendenz dazu, die evaluativ Begünstigten zeremoniell und dem Prestige nach überzubewerten und die evaluativ Benachteiligten hier und jetzt bis zur Würdelosigkeit zu behandeln.

Das personale und soziale Problem kann durch eine den Personen zugängliche Pluralität von Gemeinschaften gemindert werden, da sich dann die „Platzierungsmöglichkeiten“ und „Auffangmöglichkeiten“, z. B. in Subkulturen der Imagination, erhöhen (Plessner 1983b, 343, 348f.). Aber dann entsteht per- 
sonal und sozial noch immer, wenngleich potenziert, die Frage danach, ob wir nicht erst durch Gesellschaft im Unterschied zu der Gemeinschaft von Gemeinschaften die Grenzen der Vergemeinschaftung übertreten können. Plessner geht so weit, die Erfindung der Gesellschaft - notfalls auch aus nur einer einzigen Gemeinschaft heraus - zu denken. Selbst die Festlegung aller personalen Exzentrierungs- und Rezentrierungspotentiale auf den Wertekanon einer einzigen Gemeinschaft verhindert in der Generationenfolge nicht, dass die von der Gemeinschaft in Anspruch genommenen Resultate personaler Aktivitäten von ihr abgelöst werden, handele es sich dabei um die materiell verkörperten Resultate zur leiblich-körperlichen Befriedigung oder - und mehr noch - um den Spieltrieb der Nachwachsenden, ohne den die gemeinschaftlich definierten Rollenerwartungen nicht einmal erlernt werden können.

Die Ermöglichung von Gesellschaft kann aus dem Überschuss menschlichen Trieblebens verstanden werden, aus der „Überfülle nicht ausgenutzter Kraft“, die sich „vornehmlich im Spiel entlädt“ und mit den nachwachsenden Generationen von neuem entbunden wird, was schon Friedrich Schiller hervorgehoben hat. Das Spielpotential des Umgangs mit Ambivalenzen, der Übertretung des Geregelten, muss von neuem entbunden werden, selbst wenn damit nur die gemeinschaftsbestimmte Bannung der Ambivalenzen beabsichtigt wäre.

\footnotetext{
Mithin kann man sagen, gäbe es keine Zivilisation schon aus den einfachsten Zweckmäßigkeitsgründen, so müsste sie um des Spieltriebes willen erfunden werden und würde auch erfunden. Zeigt doch die Analyse der zivilisatorischen Grundhaltungen, Zeremoniell und Prestige, unbeschadet ihrer tiefen Notwendigkeit den ausgesprochenen Charakter der Künstlichkeit, mit der der Mensch sich umgibt [...]. Die Gesellschaft lebt allein vom Geist des Spieles. (Plessner 1981b, 93f.)
}

\subsection{Personalität als das Medium gesellschaftlicher Interaktionen: Gesellschaft im Alltag, in der Zivilisation und im funktionalen Sinne}

Im Unterschied $\mathrm{zu}$ den gemeinschaftlichen Interaktionen beruhen gesellschaftliche Interaktionen nicht auf einer gemeinsamen Bindung an die gleichen Werteprioritäten. Die damit verbundene Verhaltensunsicherheit steht jedem plastisch vor Augen, wenn er an Kinder denkt, die, plötzlich mit Fremden konfrontiert, bemerken, dass sie mit diesem nicht wie mit einem $\mathrm{Du}$ interagieren können. Man kann solche Situationen so interpretieren, dass das Kind auf ein Er/Sie/Es (3. Person Singular) trifft, das wohl einer anderen Wir-Gemeinschaft (einem Ihr: 2. Person Plural) angehört, von der es die Vergleichbarkeit (im Sie 
der 3. Person Plural) noch nicht erfahren hat. Pubertierende und Halbstarke verlieren sich nicht selten in Bandenkriegen, in denen erst nach Gewaltausübung die Erfahrung dieser Vergleichbarkeit im Plural dämmert. Aber auch als Erwachsener hat man irritierende Erfahrungen, sobald man etwa in fremden Kulturen vom üblichen, touristisch gepflasterten Weg abkommt, die Schriftzeichen nicht versteht und die Einheimischen keine westliche Sprache beherrschen, weshalb sie einen fliehen, um nicht ihr Gesicht zu verlieren.

Wenn man Gesellschaft als die wahrscheinliche Möglichkeit versteht, mit der jeweils eigenen Werteorientierung nach - Anderen und Fremden gleichwohl interagieren zu können, muss die Personalität in diesem Falle anders als Medium zur Geltung kommen (vgl. 12.3.). Kann man im Falle gemeinschaftlicher Interaktion die gemeinsame Wertebindung unterstellen, weshalb sie oft auch dem Verhalten implizit bleibt oder nur mimisch-gestisch aktualisiert wird, muss im Falle gesellschaftlicher Interaktion für sie, die gemeinsame Wertebindung, erst ein Äquivalent an gegenseitiger Orientierung gefunden oder erfunden, eben: erspielt werden. Die Entkopplung der gesellschaftlichen Interaktion von einer bestimmten und implizit vorgegebenen Semantik verlagert das Orientierungsproblem in den Prozess der Pragmatik des äußeren Verhaltens. Unter gesellschaftlichen Bedingungen gilt es, durch Medieneffekte dasjenige im Äußeren zur Erscheinung zu bringen, was man nicht als die intentional zu aktualisierende Semantik voraussetzen kann. Die Semantik muss in der Vorführung erst erzeugt und immer wieder explizit gemacht werden. Und es ist nicht von vornherein sicher, ob daraus eine gemeinsame Aufführung wird, wenn ich hier mit den beiden Übersetzungen von performance spielen darf.

Schauen wir uns aber phänomenal an, wie Gesellschaft in diesem Sinne uns heutigen Angehörigen einer westlichen Kultur auffällig wird. Sie begegnet uns zumeist auf drei Weisen, im großstädtischen Alltag, im Resultat einer politisch anhaltenden Zivilisationsgeschichte und im Sinne von funktionalen Wertsphären, deren Eigengewicht für westlich modernisierte Gesellschaften als charakteristisch gilt.

Wir heutige Städter erfahren bereits im Alltag Gesellschaft, nämlich „,zwischen den Polen der Gemeinschaft, Blut und Sache, spannt sich das ungeheure Gebiet einer noch nicht politisch oder ökonomisch fassbaren, gewissermaßen unbestimmten Öffentlichkeit“: Zwischen der Familiarität und Objektivität liegt ein Zwischenreich „zwar nicht wertloser, wohl aber moralisch wertäquivalenter, nicht nach einer Alternative so oder so entscheidbarer Situationen, in denen Seele mit Seele in unvermittelten, d. h. liebefreien und sachfreien, weder durch Sympathie noch durch Überzeugungen regulierbaren Kontakt gerät“. Nicht für jede Kollision und Konstellation gibt es vorbildliche Verhaltensmuster, wie 
gewöhnlich im Regionalverkehr des Massentransportes oder an der Kasse eines Supermarktes. Aber auch dort kommt etwas dazwischen, ein unfreundliches Wort, ein Vordrängeln, eine schöne Frau, jemand scheint etwas zu stehlen und so fort. Die Alltäglichkeit gilt als der „Inbegriff lauter einzelner Fälle“ (Plessner 1981b, 80), die gemeistert werden müssen:

Dieses Reich der Alltäglichkeit, der wertäquivalenten Situationen kennen wir alle: es ist die Gesellschaft im Sinne der Einheit des Verkehrs unbestimmt vieler einander unbekannter und durch Mangel an Gelegenheit, Zeit und gegenseitigem Interesse höchstens zur Bekanntschaft gelangender Menschen. Und wir kennen auch diesen tänzerischen Geist, dieses Ethos der Grazie: das gesellschaftliche Benehmen, die Beherrschung nicht nur der geschriebenen und gesetzten Konvention, die virtuose Handhabung der Spielformen, mit denen sich die Menschen nahe kommen, ohne sich zu treffen, mit denen sie sich voneinander entfernen, ohne sich durch Gleichgültigkeit zu verletzen. (Ebd.)

Was uns Städter, zumal Großstädter, im Alltag an Gesellschaft, an wertäquivalenten Interaktionen, begegnet, erfordert spielerische Formen der Bewältigung von Polyvalenz, die historisch im Prozess der Zivilisation herausgebildet worden sind. Nicht zufällig entstand das Problem der Gesellschaft geballt und wiederkehrend im Außenkontakt verschiedener Gemeinwesen, wofür im politischdiplomatischen und wirtschaftlich-kulturellen Austausch Verkehrsformen entstanden. Zeichnet sich Öffentlichkeit, als der „Ort der unverbunden sich begegnenden Personen“, durch „Wertferne“ aus, die keine „Wertfreiheit“ bedeutet, entsteht in ihr eine „zwiefache Gebrochenheit“. In der gesellschaftlichen Öffentlichkeit herrscht „die Unausgleichbarkeit des Gegensatzes von Situation und Norm“ und die Unausgleichbarkeit des Gegensatzes von „Privatperson und Amtsperson“ vor. Während man in einer bestimmten Gemeinschaft dank des gemeinsamen Werterepertoires die Ausgleichsvarianten beider Gegensätze kennt und erwarten darf, gibt es diese Sicherheit in der gesellschaftlichen Interaktion mit der Werteorientierung nach Anderen oder Fremden nicht. Sollen die Personen in der gesellschaftlichen Öffentlichkeit nicht gleichsam ständig ins Lachen oder Weinen geraten, muss die Situation künstlich vermittelt werden. Da der Rückgang auf eine im Vorhinein gemeinsam bestimmte Existenz oder Sache nicht weiterhilft, muss im äußeren Interaktionsgeschehen selber ein künstlicher Ausgleich gefunden werden. Plessner nennt „zweckverfolgende Handlungen von solcher Künstlichkeit“, deren Konstellation und Resultante „wesensmäßig nur ungefähr bestimmbar sind“, und die eine „Wertgerechtheit“ für beide Seiten einschließen, „Geschäftskunst“ und politische Kunst der „Diplomatie“ (ebd., 96f.). Was also in einer bestimmten Gemeinschaft durch wertekonformes Verhalten gelöst werden kann, kann in der Gesellschaft nur durch diplomatisches Verhalten erreicht werden, eben wegen des Mangels an einer 
gemeinsamen Bindung an die gleichen Wertorientierungen. Man kennt dies von jedem Basar oder einer plötzlichen Auseinandersetzung auf öffentlichen Strassen und Plätzen.

In der gesellschaftlichen Sphäre ohne Liebe und ohne Überzeugung „als bindende Weisen von Mensch zu Mensch gibt es keinen Ausgleich der Gegensätze, sondern nur ihre Vermittlung im Wege des Übereinkommens. Dieser Weg führt hart am offenen Konflikt vorbei, in dem die physische Macht entscheidet“" (Plessner 1981b, 98). Will man die Gewaltentscheidung, die im konsequenten Selbstlauf die Verkehrung des Allzumenschlichen ins Unmenschliche bringen kann, vermeiden, braucht man Diplomatie als das „Spiel von Drohung und Einschüchterung“. Diplomatie kann als diejenige „Kunst“ entfaltet werden, die „die Würde des anderen unangetastet lässt“, indem sie „die Unterlegenheit des Gegners aus seiner freien Entscheidung hervorzaubert oder die belastende Siegerrolle objektiven Gewalten zuschiebt“. Ihr Element ist das der „Geschichte“ (ebd., 99). Die sich in ihr als der Prävention des Umschlags in Gewalt ausbildenden Prinzipien sind das des egoistisch „größtmöglichen Vorteils“ und das der „Gegenseitigkeit“. Beide Prinzipien sind aber situationsabhängig zu vermitteln, da es „keine Logik der Öffentlichkeit“ gibt (ebd., 101f.).

Begegnet uns im Alltag Gesellschaft als situativer Spielzwang, so in der Diplomatie als situationsgebunden ernsthafte Schauspielerei, die es erlaubt, die Verdoppelung der Person zur vollen Entfaltung zu bringen. Diese Entfaltung gestattet es, nach Diplomatie als dem Geschäftsphänomen und Takt als dem Phänomen der Geselligkeit (ebd., 112) auch im gesellschaftlichen Alltag zu fragen, ohne beide in ihren sozialhistorisch elitären Ursprung aufzulösen. „Diplomatische Situationen entstehen und lösen sich zwischen irrealisierten Funktionären oder Geschäftsträgern nach den Gesetzen der Taktik und Strategie, Zug um Zug. Taktsituationen entstehen und lösen sich zwischen natürlichen Personen auf Grund außerrationaler, unmerklicher Vorfühlung und unter sorgfältiger Innehaltung der Distanz" (ebd., 110). Wo es weder um Logik noch um Familiarität gehen kann, wo es sich vielmehr um „grundlose Zwischenspiele unseres gesellschaftlichen Lebens“ handelt, da situativ eine „so nie wiederkommende, unvertretbare und unrubrizierbare Lage“ entstanden ist, zählt die „Weisheit des Taktes“: „Schonung des anderen um meiner selbst willen, Schonung meiner selbst um des anderen willen“ (ebd., 109f.).

Plessner erschließt diese „Hygiene größtmöglicher Schonung“ der Seelen respektive Leiber als "die erste und letzte Tugend des menschlichen Herzens“ (ebd., 107): Takt ist das

Vermögen der Wahrnehmung unwägbarer Verschiedenheiten, die Fähigkeit, jene unübersetzbare Sprache der Erscheinungen zu begreifen, welche die Situationen, die Personen 
ohne Worte in ihrer Konstellation, in ihrem Benehmen, ihrer Physiognomie nach unergründlichen Symbolen des Lebens reden. Takt ist die [...] willige Geöffnetheit, andere zu sehen und sich selber dabei aus dem Blickfeld auszuschalten, andere nach ihrem Maßstab und nicht dem eigenen zu messen. (Ebd.)

Er ermöglicht die „Kultiviertheit der Andeutung“, eine „Kultur der Verhaltenheit“: „Im Indirekten zeigt sich das Unnachahmliche des Menschen“ (ebd., 106).

Schließlich begegnet uns Gesellschaft in dem modernen funktionalen Sinne (wie ihn Max Weber eröffnet hat). Die Gesellschaft qua Öffentlichkeit, d.h. als „das offene System des Verkehrs zwischen unverbundenen Menschen“ (Plessner 1981b, 95), taucht nicht nur als heute alltägliches und als zivilisationsgeschichtliches Phänomen auf, sondern auch als ein funktionales, für die Ordnung der Moderne bestimmendes Phänomen. Es ist der Überschuss des Spieles, der, sofern er in der diplomatischen Geschäftskunst bewältigt und von ihr ablösbar wurde, eine Art Rechtsgrund für die Logik ausdifferenzierter Handlungssphären ermöglicht. Die Öffentlichkeit, zivilisatorisch einmal erkämpft, gerinnt dann funktional zu einer Vielheit von Bestimmungen:

Dieses offene System des Verkehrs besondert sich zu je eigenartigen Sphären nach Maßgabe bestimmter Wertklassen, zur Sphäre des Rechts, der Sitte und Erziehung, des Staates, der Wirtschaft und des ,Verkehrs' im engeren Sinne. Werden also die von Person zu Person unverbundenen Menschen auf diese Weise wieder unter eine gemeinsame Wertund Sachbindung gebracht, so kann doch daraus keine echte Vergemeinschaftung mehr kommen. Denn es handelt sich hier nicht wie in der Sachgemeinschaft der Kultur um gegenseitige Durchdringung mit Hilfe der Werte, um ihre Erkenntnis, ihre Verinnerlichung, sondern um Ordnung des Verkehrs auf Grund der Werte, die jedoch dafür selbst nicht mehr in den Gesichtskreis des einzelnen zu treten brauchen. (Ebd.)

Hier hat der oben genannte dritte Rollenbegriff seinen Platz, die Funktionalisierung der Person zu Leistungen, die den ausdifferenzierten Wertsphären entsprechen. Man könnte - im Unterschied zu den Gemeinschaftswerten - von den Funktionswerten der modernen Gesellschaft sprechen.

Was in der Zivilisationsgeschichte am Rande der Gewaltentscheidungen in Geschäftskünsten und diplomatischen Spielformen instabil als Öffentlichkeit errungen wurde, bildet in der Moderne zugleich die Ordnungsfunktion eigenartiger Wertsphären, eine bereits bestimmte und bestimmende Öffentlichkeit, die den Alltag schon vorstrukturiert. Diese institutionell stabilisierte Vorherbestimmung des Alltags eröffnet ein Spektrum von Gleichgewichten und Ungleichgewichten, zunächst einmal unter den Formen gesellschaftlicher Öffentlichkeit selber, jener nämlich, die noch immer nur geschichtlich stets von neuem als Zivilisation errungen werden kann, jener, die bereits im Gefolge his- 
torischer Auseinandersetzungen am Rande der Gewalt in Wertsphären inkorporiert worden ist, und dieser im Alltag unbestimmten Öffentlichkeit, in der die Urteilskraft für lauter einzelne Fälle zu entbinden ist. Diplomatisches und taktvolles Benehmen „bezeichnen die Weisen des Verhaltens des Menschen in der Öffentlichkeit, je nachdem, ob es Geschäfte zu machen oder nur einfachen Verkehr ohne Zweck, Unterhaltung um der Entspannung und Erhöhung des Lebens willen zu pflegen gilt" (ebd., 112). Was an gesellschaftlicher Öffentlichkeit geschichtlich errungen, institutionell inkorporiert und alltäglich entbunden wird, wird seinen negativen Hintergrund, von dem es sich abhebt, den möglichen Ausbruch von Gewalt, nicht los.

Die Gefahr der Gewalt geht konstitutiv in ihre gesellschaftlich-öffentliche Vermittlung ein, weshalb Plessner entschieden für die „Pflicht zur Macht“ plädiert und sich gegen die „Utopie der Gewaltlosigkeit“ wendet, die suggeriert, das Gewaltproblem durch Auflösung der Gesellschaft in eine Gemeinschaft lösen zu können. Es ist dieser Kampf zwischen verschiedenen Gemeinschaften um die Ersetzbarkeit von gesellschaftlicher Öffentlichkeit, der, aufgerüstet zum Weltanschauungskrieg, Europa nach den Religionskriegen des 17. Jahrhunderts in die Weltkriege unseres 20. Jahrhunderts gestürzt hat. Was hier gefehlt habe, war nicht das „teure Experiment der Revolution“, die „radikal“ alle auf die gleiche Weise durch eine Wertegemeinschaft bestimmen würde, sondern waren die Grenzen der Vergemeinschaftung durch Vergesellschaftung und Individualisierung:

Wie dann, wenn die Psyche Gewaltmittel als Schutzmittel der Distanz und Verhaltenheit, Vornehmheit und Künstlichkeit zu ihrer Entwicklung braucht, weil sie durch allzu große Nähe, durch restlose Aufrichtigkeit und Unverhülltheit leidet und Schaden nimmt? Wie, wenn die Seele des Menschen als das absolut Mehrdeutige, das undurchsichtig, verborgen, geschont, also, selbst wenn es eindeutig bestimmbar wäre, mehrdeutig bleiben soll, damit es seine schöpferische Kraft im Geiste behält, die Gewalt in irgendeinem Sinne bejahte? Dann müsste der Mensch um des Höheren willen in ihm die Systeme der Öffentlichkeit, von den einfachsten Höflichkeitsformen zwischen Person und Person bis zu den großen Künstlichkeiten des Staates dieser neuen Möglichkeit zuliebe auf die Utopie der Gewaltlosigkeit verzichten und mit der Welt des Kampfes, eines freilich in den Mitteln kultivierbaren Kampfes, der nicht ums Dasein, sondern ums Sosein ausgefochten werden soll, einen Frieden machen. (Plessner 1981b, 132f.)

Die Philosophische Anthropologie Plessners hat früh und energisch den ideologischen Aufrüstungen zum sog. Europäischen Bürgerkrieg (zwischen dem rein kapitalökonomischen Liberalismus, internationalem Bolschewismus und Nationalsozialismus) in den 1920er Jahren widersprochen. Dieser Ideologiekrieg hat die Welt ein Jahrhundert gekostet und den europäischen Kontinent bis 1989 welthistorisch zurückgeworfen. Ein neuer Ideologiekrieg zeichnet sich ange- 
sichts der nun dreißigjährigen neoliberalen Globalisierung in Europa und auf allen Kontinenten ab. Die gemeinsame ökologische Krise könnte ein Kooperationsgrund sein, aber auch Egoismen und Gewalt wecken. Die gemeinsame Lösungsrichtung bräuchte eine Zivilisierung der gesellschaftlichen Auseinandersetzung am Rande der Gewalt, ohne einerseits alle jeweils Anderen oder Fremden dem Assimilationszwang an eine Gemeinschaftsform auszusetzen, und ohne andererseits alle Gemeinschaftlichkeit in eine, die kapitalökonomische Gesellschaft aufzulösen. Die Individualisierung der Personen benötigt sowohl Gemeinschafts- als auch Gesellschaftsformen von der regionalen bis zur globalen Ebene.

\subsection{Das Problem der Balance zwischen Gemeinschaft und Gesellschaft durch die Kunst, das Verfahren und die juristische Methode der Politik}

Die Ideologien des Radikalismus opfern alle möglichen Unterscheidungen dem Schema eines exklusiven Gegensatzes, einer Entweder-oder-Strategie, der alles in letzter Konsequenz untergeordnet wird. Ihnen zufolge muss entweder die Gemeinschaft in Gesellschaft oder die Gesellschaft in Gemeinschaft aufgelöst werden. Plessners Philosophische Anthropologie eröffnet demgegenüber eine Art von kommunitärem Liberalismus, in dem die Pluralität der Sozialformen zugunsten der Individualisierung von Personen integriert werden kann. Sie plädiert für die Vermittlung zwischen Gemeinschafts- und Gesellschaftsformen durch die Kunst der Politik, durch das Verfahren des Staates und durch die Methode des Rechts.

Die Gesellschaft läuft nicht ,außen um die Sphäre der Gemeinschaft herum, sondern durch sie hindurch“: Diese Einsicht fällt einem leicht, sobald man sich vergegenwärtigt, dass beide Formen - Gemeinschafts- und Gesellschaftsformen - Interaktionen von sich individuierenden Personen darstellen: „In uns selbst liegen neben den gemeinschaftsverlangenden und gemeinschaftsstützenden die gesellschaftsverlangenden, distanzierenden Mächte des Leibes nicht weniger wie der Seele, in jeder Sozialbeziehung wartet die eine, wenn noch die andere gilt, auf ihre Erweckung“ (Plessner 1981b, 115). Die „extremistische Geisteshaltung“ verspricht in den üblichen Dualismen die Erlösung von der Wurzel allen Übels dadurch, dass man Tabula rasa, so etwas wie reinen Tisch mit dem jeweils anderen Gegensatzpol mache. Sie entspricht so nur der „Dissoziierung der modernen Gesellschaft“: „Die moderne Welt lebt in der Isolierung ihrer eigenen Komponenten den Radikalismus, die Entgeistung der Wirklichkeit und 
hat darum zu ihrer Apologie wie zu ihrer Opposition radikalistische Theorien nötig“(ebd.,18).

Aus dem Radikalismus der sich zauberhaft alles subsumierenden Einheitsformeln führt erst die Anerkennung des Heteronomen verschiedener Sphären heraus. „Jede Sphäre hat ihre spezifischen Entscheidungsinstanzen, die Gemeinschaft regelt sich nach Einsicht und Liebe, die Gesellschaft nach spielgerechtem Kampf und Takt. Zwischen den Sphären führt keine Brücke, sie gehorchen nicht wieder einer dritten übergeordneten Gesetzmäßigkeit“ (ebd., 116). Wir kommen nicht um unsere urteilskräftige Teilnahme an der Politisierung der nötigen Verschränkung, an dem staatlichen Verfahren und der juristischen Methode der Vermittlung zwischen beiden Sozialformen hier und heute herum, weil nichts Geringeres als die Koexistenz im Menschsein auf dem Spiele steht.

Es gab im 20. Jahrhundert furchtbare, weil der Möglichkeit des Menschseins zerstörerische Fehlpolitisierungen, denkt man an den nationalsozialistischen Rassenkrieg und den stalinistischen Klassenkrieg, an Auschwitz und den Archipel Gulag. Die Auflösung des Privaten und des Öffentlichen in eine einzige Bewegungspolitik bringt den Springquell der menschlichen Existenz zum Versiegen. Das anthropologisch elementare Doppelgängertum muss von jeder solchen politischen Bemächtigung freigehalten werden. Das Politische entspringt dem Öffentlichen und gewinnt erst an dem Problem, welche Verschränkung von Vergemeinschaftung und Vergesellschaftung hier und heute die angemessenste ist, sein gewichtiges Thema, das der öffentlichen Partizipation aller bedarf. Es ist diese Frage „einer Ethik des Ausgleichs, der wahren Mitte“ (ebd., 126), die zu Recht im Mittelpunkt der Phänomene des Politischen steht. Dies sei auch gegen die ständigen Scheinpolitisierungen drittklassiger Themen gesagt, die von dem Problem der gerechten Proportion gemeinschaftlicher und gesellschaftlicher Güter ablenken.

Unter Politik als Tätigkeit kann man die Kunst verstehen, „aus Gelegenheiten Ereignisse zu machen und im Element einer unausgesetzten Willkür mit den tatsächlichen Mächten, Triebkräften, d. h. in den Grenzen des Möglichen, einen Sinn hervorzubringen“ (Plessner 1981b, 125f.). Der Staat ist „keine Substanz“, sondern ein „Verfahren“ (ebd., 115): Diese Prozedur beginnt in der unbestimmten Öffentlichkeit des Alltäglichen, die die Urteilskraft für lauter einzelne Fälle braucht, und konsultiert die schon nach spezifischen Funktionswerten bestimmten Öffentlichkeiten mit ihrem je eigenen Sachverstand. Dieses Verfahren endet auf Revision durch eine neue Bestimmung in der Rechtssetzung, die gewaltenteilig von statten geht.

Dieser Verfahrensweg ist nötig, um die Forderungen der Öffentlichkeit aus ihrer Unabsehbarkeit und Unbestimmtheit herauszuheben und dem Gemein- 
schaftsverlangen jedes Menschen, seinem Naturrecht auf Wärme und Vertrauen anzugleichen und die Gefahr beständiger Reibungen und Beeinträchtigungen der beiden Sphären zu bannen“ (ebd.):

Staat ist systematisierte Öffentlichkeit im Dienste der Gemeinschaft, Inbegriff von Sicherungsmaßnahmen der Gemeinschaft im Dienste der Öffentlichkeit. Die Methode dieses Ausgleichs zwischen den von der menschlichen Natur gleichmäßig getragenen Forderungen nach Rückhaltlosigkeit und Verschlossenheit ist das Recht, in dessen Idee das Billige, was einem natürlichen Ausgleich durch Überzeugung, Stimme der Einsicht, Stimme des Herzens entspricht, und das Gerechte, das Ausgewogene, was einem Übereinkommen aus verschiedenen Kräfterichtungen als schließliche Resultantenlage äquivalent ist, vereinigt werden. (Ebd.)

Recht ist das Medium der Übersetzung zwischen Gemeinschaft und Gesellschaft, zwischen der intrinsisch evaluativen Motivation und dem fairen Interessenausgleich mit Anderen und Fremden. Auf der ,imaginären Schnittgeraden von Gemeinschaftskreis und Gesellschaftskreis liegt das Recht als die ewig in Wandlung begriffene Einheit von Gesetzgebung und Rechtsprechung“ (ebd., 116)..$^{5}$

Werden die einander gegenläufigen Interaktionsformen von Vergemeinschaftungen oder Vergesellschaftungen auf dem öffentlichen Wege der Politik (als der Kunst des Möglichen), des Staates (als dem gewaltenteiligen Verfahren) und des Rechts (als der methodischen Übersetzung) je neu verschränkt, entsteht ein konstruktives Potential, das im Gegensatz zu den ideologischen Praktiken des Ausschlusses oder der Bemächtigung des jeweils anderen, sei es einer exklusiven Vergemeinschaftungsart (Existenz- oder Sachgemeinschaft) oder einer ausschließlichen Vergesellschaftungsart (Wirtschafts- oder formaler Rechtsliberalismus), den Prozess des Menschseins für historische Revisionen offenhält, statt ihn in letzter Instanz abschließen zu wollen. Nicht entweder dieses Vergemeinschaftungsniveau oder jenes Vergesellschaftungsniveau wird zum transzendenten Maßstab der ganzen Entwicklung genommen, sondern die Infragestellung bestimmter Maßstäbe hält den Prozess der geschichtlichen

5 In der Gegenwartsphilosophie versteht Habermas, allerdings ohne Bezug auf Plessner, das Recht als Verfahren und ,als Transformator im gesellschaftsweiten Kommunikationskreislauf zwischen System und Lebenswelt“ (Habermas 1992, 108, vgl. 78). Plessners Vermittlung zwischen der Bindung an die Wertäquivalenz oder an die Wertnähe der Interaktionen durch das Recht entspricht bei Habermas: „Die Rechtsgültigkeit einer Norm - und darin besteht ihr Witz - besagt nun, dass beides zugleich garantiert ist: sowohl die Legalität des Verhaltens im Sinne einer durchschnittlichen Normbefolgung [...], wie auch die Legitimität der Regel selbst“ (ebd., 49). 
Neubestimmung in Gang. Die Verallgemeinerung einer Sozialform zur alles Bestimmenden provoziert ihre Begrenzung durch einerseits Individualisierungsprozesse der Personenrollen, durch das individuum ineffabile, und anderseits durch das Verfahren der Öffentlichkeit.

Die Ambivalenzen des leiblich unvertretbaren Lebens der Individuen korrespondieren mit den Ambivalenzen der Öffentlichkeit, dort freilich bereits in verkörperter Gestalt, zu der sich das Leibliche immer erst erlösen muss. Wird hier durch die Kunst der Existenzführung Lebensgeschichte gestaltet, so dort durch die Kunst der Politik Geschichte der Zivilisation so gut als möglich nicht nur erlitten, sondern auch gemacht. Entsteht das Potential zur Neubestimmung hier im innerpersonalen Positions- und Perspektivenwechsel, durch den sich die Person individualisiert, also im Unterschied zu den Formen ihrer Vergemeinschaftung und Vergesellschaftung ihrem Leben unvertretbar einzigartigen Ausdruck zu geben versucht, entsteht es dort im interpersonalen Wechsel zwischen verschiedenen Gemeinschafts- und Gesellschaftsperspektiven, um eine zivilisationsgeschichtliche Individuation zu ermöglichen. Die „wertedemokratische Gleichstellung aller Kulturen“ erfolgt nicht vor einer universalistischen Regel (eine solche Metaregel für Heteronomes gibt es nicht), sondern „in ihrer Rückbeziehung auf einen schöpferischen Lebensgrund“, weshalb sie „von Individuation zu Individuation“ fortschreiten kann (Plessner 1981d, 186). Da es keine einzige Metaregel (außer in einer totalitären Ordnung) für alle Sozialformen gibt, sondern nur deren historische Pluralität, muss man in dieser mit dem „Widerstreit“ zwischen den Sozialformen rechnen, statt auf einen „Widerspruch“ setzen zu können, für den es eine innersystemische Lösungsform gäbe (Lyotard 1987).

\subsection{Die dynamische Fassung der soziokulturellen Mitwelt: Kulturelle Entfremdung und Geschichtlichkeit in der Generationenfolge}

Die Unterscheidung zwischen gemeinschaftlichen und gesellschaftlichen Interaktionsformen von Personen ist zwar die erste komplexe Ausführung der soziokulturellen Mitwelt in der Philosophischen Anthropologie, aber diese Fassung hat noch eine gewisse Statik, bedenkt man das Problem der Generationenfolge in einem soziokulturellen Sinne. Die Differenzierung zwischen Vertrautem und Unvertrautem gerät durch die Generationenfolge in eine Dynamik hinein, aus der sich nicht zwangsläufig Brüche ergeben müssen (die von näheren Bedingungen abhängen). Aber die dynamische Fassung ermöglicht zumindest Ver- 
änderungen in der Generationenfolge. Jede Generation durchläuft die Phänomene menschlichen Daseins von neuem, ohne dass sie von vornherein entweder auf die einfache Reproduktion der Tradition oder auf den totalen Bruch mit der Tradition festgelegt werden könnte. Die Nachwachsenden teilen sich zwischen diesen Extremen auf, je nachdem, wie sie mit ihren Freiheits- und Grenzerfahrungen zu leben verstehen und je nachdem, wie sie neue Umstände zu nehmen lernen. Hört der Nachwachsende wie Hamlet die Stimme des väterlichen Geistes, dem er verpflichtet ist, oder tut er sie von vornherein als Spuk ab? Wie soll man mit dem Erbe umgehen, nimmt man es an, wodurch man sich auch auf einen Rahmen festlegt? Wieviel von der Tradition wird ausgeschlagen, um freier zu werden oder auch nur in bekannter Manier sich neuen Umständen anzupassen?

Die Philosophische Anthropologie, die die Körper-Leib-Differenz hoch veranschlagt, muss daher auch der Generationenfolge große Aufmerksamkeit schenken. Jede Person hat nur ihren, diesen einen Körperleib, bestenfalls in einer Reihe von Lebensaltern. Wir mögen kulturell noch so viel sublimieren und symbolisch anhand von Leibesmetaphern auf andere übertragen, wir mögen noch so intensiv ein Leben lang in den sprichwörtlichen Mutterleib zurück wollen, von dem uns nun auch noch die neuen Reproduktionstechnologien befreien könnten: Von unserer leiblichen Bewegtheit bleibt für andere, auch die Nachwachsenden, nichts anderes übrig als eine kulturelle Verkörperung. Der Lebenszyklus ist nicht auf das Format einer Schwangerschaft, die innerleibliche Interaktion, oder auf einen orgiastischen Liebesakt, die zwischenleibliche Interaktion, zu bringen.

Umgekehrt, die Überorientierung aufs Inner- und Zwischenleibliche ist eine Flucht vor der Einsamkeit des je einmaligen Körperleibes. Als ließe sich dessen Körper-Leib-Differenz dualistisch aufspalten, der er aber doch seinen lebendigen Charakter verdankt! Diese Flucht steht schon selber im Zeichen des Todes und vermag ihn so nicht zu verstehen. Für die Individualisierung ist die leibliche Sinnbildung primär, aber soziokulturell überlebt die Verkörperung in ihrer praktischen Bedeutung. Unsere zentrische Organisationsform lebt schon immer auf die exzentrische Positionalität hin, von der her sie sich als Leib und Körper zu differenzieren vermag. Und umgekehrt „braucht“ diese Positionsform weltlicher Bewegungsmöglichkeiten eine Organisationsform, die Bewegungen ausführt. Diese Organisationsform und diese Positionalitätsform sind füreinander „notwendige Möglichkeiten“, nicht aber zwei Möglichkeiten ein und derselben Notwendigkeit, von der allein Gott reden könnte. Die Anlässe, die zur Eingespieltheit beider aufeinander führen, sind „Gelegenheiten“ (Plessner 1975, 151), die sich nicht nochmals einer Metaregel von kausaler Notwendigkeit fügen. 
Insofern muss uns die Eingespieltheit der Organisations- und Positionsform aufeinander, in der die Mitwelt gleichsam gestiftet wird, und dies mit jeder Generation, letztlich mit jedem Körperleib erneut, eine in letzter Konsequenz wunderliche Grenze für unser Handeln bleiben. Sie erscheint, bei allem, was wir tun, hinaus- und verschieben, befördern und verhindern können, als ein „Schicksal“, weder in dem spezifisch griechisch-antiken noch christlichen Sinne, sondern einfach in der Bedeutung, dass auch jede medizinische Kunst - von der Hebamme bis zum Pathologen - einmal an ihr Ende gelangt. Es gibt unerwartet plötzlich Herztode, mit denen kein Kardiologe gerechnet hat. Es gibt Krebspatienten, die Jahrzehnte lang ihr Todesdatum überleben, das ihnen ein Dutzend Spezialisten längst ausgestellt hatte.

Gleichwohl setzt sich eine von solcher therapeutischen Erfahrung und kausalen Erklärung verschiedene Koinzidenz der aktualen Einspielung und ihres Zusammenbruchs durch, für die die wahrscheinlichkeitstheoretischen Aussagen der Versicherung im Einzelfall nicht viel besagen.

Jugend, Reife und Alter sind die Schicksalsformen des Lebens, weil sie dem Entwicklungsprozess wesentlich sind. Schicksalsformen sind nicht Formen des Seienden, sondern für das Seiende; das Sein tritt unter sie und erleidet sie. Neben die wasgesetzliche (wesensmäßige) und die vorgangsgesetzliche (folgemäßige) tritt als dritte Art der Notwendigkeit das Schicksal. Nach der ersten Art ist alles, was Etwas ist, bestimmt. Nach der zweiten Art ist alles, was in der Zeit verläuft, bestimmt. Nach der dritten Art sind nur die lebendigen Dinge bestimmt. (Ebd., 154)

Ja, die Nachwachsenden stammen von unserem genetischen Code ab, aber der ist der biotische Code der Verkörperung, nicht der Verleiblichung des Menschen. Jemand mag genau unseren Körper noch einmal haben, also nicht unser gewöhnliches Kind, sondern unser Klon sein: Daraus folgt nicht, dass er lebensgeschichtlich den leiblich gleichen Sinnhorizont aufbauen wird, lebensgeschichtlich gesehen die gleichen Leibesmotivationen und Ausdrucksformen wie unsereins haben wird. Das Genom wird epigenetisch ausgelesen und die Epigenese hängt von den lebensgeschichtlichen Interaktionsweisen ab. Dies fällt nicht nur bei fremderzogenen Kindern, insbesondere getrennt lebenden eineiigen Zwillingen auf, sondern auch den Eltern bei den zu Hause und betont gleich erzogenen eineiigen Zwillingen. Selbst wenn die neuen Reproduktionstechnologien biotisch die Differenz zwischen Körper und Leib in der Generationenfolge verschieben werden, bleibt die soziokulturelle Dimension dieser Differenz zu beachten. Kinder mögen von uns abstammen und von uns noch erzogen worden sein, was aber die Erziehung angehend in der Zivilisation relativ zurückgeht, während die Gruppenbildungen mit Gleichaltrigen wichtiger werden. Kinder sind selbst dann anders als wir, wenn sie uns am ähnlichsten scheinen. 
Ein Kind mag die Redeweise und das Selbstbewusstsein der Mutter imitieren. Gerade dadurch, dass es diese imitiert, hat es sie nicht selber wie die Mutter ausgebildet, ist also nicht sie. Dieser Mutter ähnelte mehr ein sich von ihr emanzipierendes Kind. Aber ein emanzipiertes Kind ähnelte ihr wieder nicht in anderer Hinsicht. Die größte Empathie von Kindern in Eltern verzögert die Emanzipation von den Eltern oder bedeutet diese Emanzipation, wenn die Eltern wenig Empathie hatten.

Kinder sind nicht unser Leib, wie vielleicht die Redeweise vom eigenen Fleisch und Blut nahelegt, oder auch die symbolische Übertragung beim Abendmahl. Kinder sind anders, weil sie dazu bestimmt sind, sich dahin zu entwickeln, dass sie ihren eigenen Körper haben können. Deshalb, ihren eigenen Körper zu haben erlernend, machen sie auch Anleihen bei unserer leibesgeschichtlichen Motivation, aber nicht nur bei uns, sondern bei allem, was ihnen begegnet. Und selbst dann, wenn die Anleihe bei uns, den Eltern am größten ist, können sie unsere lebensgeschichtliche Sinnmotivation nicht ungebrochen, d. h. nur unmittelbar als Leib, sondern indirekt, d. h. auch mittelbar durch die Verkörperung unseres Leibesausdrucks hindurch, erfahren.

Der Hauptweg in der Kulturtradierung von einer Generation zur nächsten geht über die Verkörperung, nicht über die Verleiblichung:

Existentiell bedürftig, hälftenhaft, nackt ist dem Menschen die Künstlichkeit wesensentsprechender Ausdruck seiner Natur. Sie ist der mit der Exzentrizität gesetzte Umweg zu einem zweiten Vaterland, in dem er Heimat und absolute Verwurzelung findet. Ortlos, zeitlos, ins Nichts gestellt schafft sich die exzentrische Lebensform ihren Boden. (Plessner 1975, 316)

Was bleibt, im Extremfall von ausgestorbenen Kulturen besonders deutlich, sind bestenfalls die Verkörperungen, von den Werkzeugen und Gebrauchsgegenständen über die Unterkünfte und Gräber bis zu den Bildern und Masken, dem Spielzeug.

Es sind die „Monumente“ und „Dokumente“ (Plessner 1982j, 461f.) der soziokulturellen Ausführung exzentrischer Positionalität, die am ehesten überdauern, weshalb die Nachkommen nicht von vorne anfangen müssen. Aus den Verkörperungen heraus kann man indirekt, also nicht eindeutig, auf die Intentionen und Motive derer rückschließen, die sich in diesen Verkörperungen ausgedrückt haben. Die Verkörperungen sind Medien, die Motive und Intentionen brechen, also gerade keine Eins-zu-Eins-Zuordnung zwischen den möglichen Motiven und Intentionen der Schöpfer und den uns beobachtbaren Verhaltensmedien ermöglichen. In der lebendigen Traditionsübernahme werden sich die Kinder der Körper-Leib-Differenz ihrer Eltern wohl sicherer sein als bei ferner 
Stehenden oder gänzlich Fremden. Gleichwohl, irgendein Geheimnis nimmt jeder mit ins Grab, und Nahestehenden fehlt häufig gerade jener verfremdende Blick, der es noch aufgedeckt hätte. Immer sind wir zu nah oder zu fern dran, um ein für alle Mal eindeutig zu enträtseln. In der westlichen Moderne ist man geneigt, auf Wahrscheinliches zu vertrauen, wo man früher auf Götter oder Dämonen sah.

Noch immer mögen wir annehmen, dass die Kinder vor allem von ihren eigenen Eltern erzogen werden, weil diese Annahme es plausibel machen könnte, dass die Tradierung zur Reproduktion des Gleichen schon führen wird. Es kommt der These von der einfachen Tradierung des Gleichen nicht nur der Leib im Unterschied zur genetischen Reproduktion des biotischen Körpers und im Unterschied zur soziokulturellen Verkörperung durch Medien dazwischen. Das Hauptargument von Plessner hatte ich schon unter den Grenzen der Gemeinschaft (oben 12.4.) angeführt: Es ist das Spielen in und mit den Verkörperungen, das überhaupt aus dem Kind einen Erwachsenen werden lässt. Das Spielen hat aber bei aller gegenseitigen Bindung an Gegensinn eine Freiheitsdimension, die man schwer berechnen kann, etwa um narzisstisch die Reproduktion des Gleichen, von einem selbst im Kinde, zu sichern. Man mag das Spielen autoritär eingrenzen und wird sich doch nicht sicher sein können, ob das Kind seine Folgsamkeit nur spielt und seine Opposition oder sein Weggang demnächst erfolgen wird. Man mag das Spielen antiautoritär entgrenzen wollen und kann sich doch nicht sicher werden, ob das Kind nicht autoritär folgt, wenn nicht den eigenen Eltern, so längst anderen Bezugspersonen, gerade weil es das erfahrene Haltungsdefizit intuitiv ausgleichen will.

Das Spielen als wichtigster Lernmechanismus lässt so oder so deutlich werden, dass eine einfache Tradierung des elterlichen Ebenbildes der mit Abstand unwahrscheinlichste, gleichsam schon pathologische Fall ist. Die Tradierung wird umso mehr aber zusätzliche Variationsbreite gewinnen, je mehr wir zugeben, dass Kinder letztlich nicht durch ihre eigenen Eltern erwachsen werden. Dies ist nicht nur so gemeint, dass sie schließlich nur selbst erwachsen werden können, sondern auch, dass sie dafür anderer Selbstbeziehungen bedürfen, schon in Naturvölkern zu anderen Kindern und zu anderen Erwachsenen, zu anderen Dörfern und Stämmen, sei es im Handel oder durch Verwandtschaft, oder sei es gar im $\mathrm{Krieg}^{6}$, umso mehr in unserer Zivilisation, wo sie verschiedene

\footnotetext{
6 Die vergleichende Verhaltensforschung bietet ein reiches Material auf gegen die beiden verbreitetsten Selbstschmeicheleien der westlichen Moderne, erst sie hätte die Kindheit und die Interaktion mit Fremden entdeckt. Siehe dagegen zu „vorindustriellen Gesellschaften“ Eibl-Eibesfeldt 1995, 498f., 589f., 820.
} 
Gemeinschaften durchlaufen, im Internet kennen lernen können und umso mehr vor dem Problem der Gewinnung gesellschaftlicher Selbständigkeit stehen.

Wie immer die kulturgeschichtlichen Besonderheiten dieser oder jener Gesellschaft aussehen mögen, für die philosophisch-anthropologische Hypothese ist das folgende entscheidend: In der Tradierung zur nächsten Menschengeneration wird diejenige kulturelle Zuordnung, die die Elterngeneration zwischen Leibsein und Körperhaben errungen hat, brüchig. Für die Tradierung ist eine deutliche Asymmetrie zwischen Verkörperungen und Verleiblichungen charakteristisch, nämlich zugunsten der Verkörperungen. Primär übertragen und von den Nachfolgenden angeeignet werden die Verkörperungen in dem weitesten Sinne, dass etwas auch für andere Bedeutung haben kann. Sekundär bleiben hingegen die Verleiblichungen in dem weitesten Sinne, dass etwas für mein oder unser Leibsein Sinn macht. Diese Asymmetrie ist nur ein anderer Ausdruck für die Hypothese von der Individualisierung der soziokulturellen Rolle des Doppelgängers. Tradiert wird die Rolle; ihre Individualisierung kann man dem Nachwachsenden nicht abnehmen, weil seine Nachahmungen ihm dabei nicht helfen. Die Asymmetrie in der Tradierung von Körper und Leib korrespondiert auch mit dem Status des Spielens: Spielen ist kein inner- oder zwischenleibliches Geschehen, was die Freiheit zur Selbstbindung gerade nehmen würde. Spielen ist eine Interaktion in, aber eben auch mit Verkörperungen, die nur indirekt, als sächliches oder personenhaftes Medium, mit Brechung also, leiblich-sinnliche Motivationen zum Ausdruck bringen und insofern auch erschliessen lassen können.

Natürlich gilt es auch, die Kehrseite des postulierten kulturellen Bruchs zwischen den Generationen zu bedenken. Die Kehrseite bedeutet nicht nur, dass die Elterngeneration ihre leiblich-sinnlichen Motive und Projektionen entwertet findet und insofern den üblichen Undank als der Welten Lohn erntet. Man kann das Problem auch unabhängig von den Eltern formulieren, ob nämlich die Nachwachsenden das, was hier als das Defizit in der Tradierung in Erscheinung tritt und offenbar nur von ihnen selbst überwunden werden kann, auch wirklich beheben werden. Einerseits eröffnet der kulturelle Bruch zwischen den Generationen für die folgende Generation die Freiheit zur Fortsetzung und/oder zum Abbruch. Andererseits ist gerade durch ihn nicht einmal die einfache oder auch nur quantitativ erweiterte Reproduktion des Tradierten sicher, ja, könnte die nachwachsende Generation Gefahr laufen, das Tradierte überhaupt zu verspielen, sei es durch Überwältigung von außen, sei es, weil sie nicht ihre eigenen, leiblich sinnvollen Motive und Intentionen ausbildet und somit auch den überkommenen Verkörperungen kein Leben einhauchen kann. 
Darin besteht ja die Asymmetrie: Die Elterngeneration gibt in exemplarischer Praxis Fähigkeiten zur Verkörperung weiter, die auch für andere, nicht zuletzt die Kinder, Bedeutung haben können: Arbeitsfähigkeiten, Spielfähigkeiten, Interaktionsfähigkeiten, kurz: Arten des Könnens werden tradiert. Welches Können man aber ausbildet, in welchem Maße und in welcher Proportion der verfügbaren Könnensarten, hängt davon ab, welches Motiv man hat, es zu betreiben, letztlich davon, ob die mögliche Verkörperung leiblich Sinn macht.

Für den einzelnen Menschen erfolgt die Ausbalancierung von Verkörperungen, etwa der Rolle, durch leiblich-sinnliche Motivation, indem er sich individualisiert. Entsprechend selektiv nimmt die Nachwachsende die Rolle in ihrer Imagination an und wahr. Das vergleichbare Problem haben nun aber nicht nur einzelne Menschen, sondern ganze Generationen. Durch den kulturellen Bruch zwischen den Generationen kann es Erschütterungen der tradierten Rollen selbst geben, zugespitzt in für die Nachwachsenden ungerechten und folgenreichen Kriegen bis in die soziokulturelle Elementarrolle hinein. Der generationenweise Kulturbruch ist die Herausforderung, durch die unsere Körperleiber immer wieder in Frage gestellt werden. Menschen sind damit der Geschichte bedürftige Wesen. Ihre Geschichtlichkeit antwortet auf die Not des Bruchs, wenn überhaupt etwas dieser Not genügt. Das kulturelle Selbstverständnis der Elterngeneration wird in dem Maße historisiert, als die nachfolgende Generation erwachsen wird, d. h. den tradierten Verkörperungen einen Sinnhorizont in ihrer Vergenwärtigung verleiht. Dadurch wird günstigstenfalls das Defizit, das in der kulturellen Tradierung primär der Verkörperungen entstanden ist, in neuen leiblich-sinnlichen Ausdrucksformen ausgeglichen. Natürlich ist dieser neue Sinnhorizont unter den Jüngeren selber umstritten, nicht zuletzt in Abhängigkeit von ihren jeweiligen Individualisierungen und soziokulturellen Schichtzugehörigkeiten. Es kann und muss sich erst durch Expressivität zeigen, wer repräsentativ, randständig, exklusiv etc. für die Jüngeren sich auszudrücken vermag.

Für die Philosophische Anthropologie sind also der kulturelle Bruch (mit seiner Asymmetrie in der Körper-Leib-Tradierung von Generation zu Generation) und die Geschichtlichkeit der Generationen zwei Seiten einer Medaille. Sie sind eben wie die Frage nach der exzentrischen Positionalität und wie die Antwort zur exzentrischen Positionalität, von der her der nötige körperleibliche Ausgleich gelingen könnte. Der kulturelle Bruch führt in die Not hinein, der Tradierung von Verkörperungen der vorangegangenen Generation einen lebensmotivierenden Ausdruck zu verleihen. Der Not dieses Ungleichgewichts zwischen Verkörperung und Verleiblichung antworten die Selbstausdrücke der Nachwachsenden. Die Geschichtlichkeit erwächst aus der spontanen Expressi- 
vität, bis es zu Verstärkungen, Überlagerungen und Resonanzbildungen zwischen Generationenteilen der Jüngeren kommt, diese zu ihrer Geschichte und ihrer Sinnbelegung der tradierten Verkörperungen gelangen.

Indessen sind diese Formulierungen des Problems noch zu stark von der Elterngeneration her gedacht, insofern mit deren kulturellem Erbe gebrochen wird. Es muss nicht erst die Infragestellung da sein, die wir in der westlichen Moderne strukturell schon begünstigt haben, eben als unsere fortlaufende Absetzung vom Alten, und sei es durch Scheininnovation. Die Infragestellung macht auch umgekehrt erst insoweit Sinn, als eine andere Antwort expressiv bereits dämmert.

Denn das Erfragte hängt - nicht von der Frage (bzw. an der Frage) ab, sondern von der Antwort ab. Genauer: auch von der Antwort ab. Das, was der Mensch ist oder ich bin oder wir sind, bestimmt die Antwort und wird von der Antwort bestimmt. (König/Plessner 1994, 192f.)

Das Phantasma des Ausdrucks besteht in dem Paradox eines „wahren Regenbogens, der keine Rückseite hat, als echtes Quale“, das das faktische Fragen und Antworten in einem „moralontischen ,Als““ vor dem Unterschied zwischen Theorie und Praxis erscheinen lässt (ebd., 193), und sei es zunächst auf einem Rockkonzert. Die Nachwachsenden versuchen, es durch geschichtliche Zuschreibungen zu lösen, die im ersten expressiven Anlauf noch nicht gelingen. Der Mensch ist „durch seine Expressivität“ ein „Wesen, das selbst bei kontinuierlich sich erhaltender Intention nach immer anderer Verwirklichung drängt und so eine Geschichte hinter sich zurücklässt. Nur in der Expressivität liegt der innere Grund für den historischen Charakter seiner Existenz“ (Plessner 1975, 338).

\subsection{Der utopische Charakter unserer Eingespieltheit und seine Verdeckungen: die Schrift und die Verselbständigung des Bewusstseins}

Die bislang entwickelten soziokulturellen Unterscheidungen, vom personalen Doppelgängertum, dem Unterschied zwischen Gemeinschaft und Gesellschaft, zwischen den Generationen und damit zwischen kultureller Entfremdung und geschichtlicher Expressivität, befreien die nachwachsenden Generationen nicht davon, nach der Legitimität ihrer Selbstermächtigung dafür zu suchen, alle möglichen Zuschreibungen oder Zuordnungen geschichtlich vorzunehmen, um ihre eigenen geschichtlichen Aufgaben freilegen zu können. Und sei es nur in 
der Bedeutung, dass sie die behandelten oder ähnliche Unterscheidungen inhaltlich neu belegen und ausfüllen wollten. Umso mehr aber dann, wenn den Nachwachsenden diese Unterscheidungsrichtung der Philosophischen Anthropologie zu plural und zu kontingent gerät. Es handelt sich in dem oben genannten Sinne (12.7.) um notwendige Möglichkeiten der Eingespieltheit unserer zentrischen Organisationsform und unserer exzentrischen Positionalitätsform aufeinander. Möglichkeiten, die zur Eingespieltheit notwendig sind, ergeben keine einzige und zugleich alles übergreifende Notwendigkeit der Einspielung in der Lebensführung. Wer für seine Lebensführung das „Bewusstsein“ von einer „unerschütterlichen Gewissheit“ braucht, das eine höhere Notwendigkeit zu vermitteln vermag, wird die notwendigen Möglichkeiten der Eingespieltheit des menschlichen Lebens, die die Philosophische Anthropologie erschließt, als die „Nichtigkeit“ des Nihilismus verkennen, die durch „Transzendenz“ aufgewogen werden muss (Plessner 1975, 341f.).

Man kann die Suche nach letztinstanzlicher Legitimität zur geschichtlichen Selbstermächtigung bewusstseinsphilosophisch missverstehen, nämlich als eine letzte Entscheidungsschlacht, für die man das Bewusstsein rüsten müsste. Das Entscheidungsproblem nimmt dann die Form der Frage entweder nach einer letzten Metaregel als dem rationalistischen Entscheidungsgrund an, oder es bleibt dem Menschen nur „der Sprung in den Glauben“, „will er die Entscheidung so oder so“ (ebd., 342). „Bewusstsein der Individualität des eigenen Seins und der Welt und Bewusstsein der Kontingenz dieser Gesamtrealität sind notwendig miteinander gegeben und fordern einander“ (ebd., 345).

Verselbständigt man das Bewusstsein gegenüber seiner Funktion im Verhaltenskreis, die Eingespieltheit des Menschen auf die Mitwelt und damit auf die Differenz zwischen Innen- und Außenwelt zu aktualisieren, wird diesem Bewusstsein alles zufällig und möglich. Ohne Verhaltensbezug verliert es allein auf sich selbst bezogen jeden Boden unter den Füßen. Es entfremdet sich selbst in bloßer Kontingenz. Es wird sich befremdlich bis zum „Verhängnis“, wie der Selbsttöter Alfred Seidel schrieb (Seidel 1927).

$\mathrm{Zu}$ dieser Verselbständigung des Bewusstseins verleitet die Verschriftlichung der Sprache. Sprache in actu als Rede unter Anwesenden gebraucht, bleibt allen Beteiligten im gegenseitigen Blickkontakt ihr Verhaltenskontext gegeben: Das Schaubild der Rollen und die Rollensprachen werden ineinander übersetzt. Demgegenüber kann Sprache in der Schrift ihren Charakter verlieren, als personales oder sachliches Medium der kommunikativen Interaktion zwischen Personen zu dienen. Was Medium war, indem es Ausdruck und Handlung personal verschränkte, wird dann wie ein Handwerkszeug Denk- oder Schriftzeug, das Verhalten nur noch bezeichnet, sei es zu seiner Instrumentierung 
oder sei es zu seiner Ersetzung. Was Medium des rückbezüglichen Stimmungskreises der Personen war, wird so zum Objekt und Instrument im Auge-HandSehfeld, von dem man sich distanzieren und etwas ablösen kann. „Sprechend hebt die Sprache ihr eigenes Werk, den physischen, durch Tradition bekräftigten Ausdruck wieder auf. Ihre Vermittlung dient immer der Einsicht in die Sache selbst, die nicht anders zu erreichen ist als eben durch die Brücken schlagende Sprache“ (Plessner 19830, 405). Die Freisetzung des Sachgehalts der Sprache vom noch aktual zu lebenden Verhaltenskontext der Rede erfolgt in der Schrift:

Der Zauberstab, der Sprachschranken in überschreitbare Sprachgrenzen verwandelt, ist die Versachlichung. Eine Gefahr ist für den Menschen allerdings mit diesem seinem Monopol verbunden: Die Gleichsetzung von Sache und Ding. Denn über beide verfügt der Mensch nun einmal. Verdinglichung im Zeichen der Versachlichung ist überall dort gegeben, wo der Mensch in seiner Zwienatur den Menschen als Mittel gebraucht. Diese Instrumentalisierung allerdings lässt sich nicht nur nicht vermeiden, sondern ist Grundlage menschlicher Gesellschaftsbildung und damit gesellschaftlichen Entwicklungen ausgeliefert. Da letztere in fortschreitendem Maße mit der Technisierung verbunden sind, ist es zu einer Verdinglichung im Zeichen des Fortschritts gekommen.“ (Ebd., 408)

In gewisser Weise wird die obige Unterscheidungsreihe von der Personalität bis zur geschichtlich legitimen Selbsterkundung an der Verschriftlichung der Sprache entdeckt. In der frühen Neuzeit wird oft die Freilegung der exzentrischen Positionsform gegenüber der soziokulturellen Tradition noch metaphysisch reintegriert oder in positiven Ausmalungen des utopischen Standorts, des Nirgendwo und Nirgendwann, vorgenommen. Gegenüber diesen frühen Versuchen, das Nirgendwo und Nirgendwann der Utopie in die gemeinschaftliche Tradition einzuholen, setzen sich nach den klassischen Ausgleichsversuchen (Ende des 18. und zu Beginn des 19. Jahrhunderts) ab Ende des 19. Jahrhunderts bis in die Mitte des 20. Jahrhunderts die Versachlichungen und Verdinglichungen der schriftlich zur Ambivalenz der Gesellschaft emanzipierten Sprache durch. Diese Versachlichung qua Verdinglichung der Gesellschaft hat seit der Romantik entsprechend expressionistisch-symbolistische Gegenbewegungen ausgelöst.

Die Philosophische Anthropologie kritisiert solche Gegenbewegungen nicht, weil sie die Verdinglichung der Versachlichung bejaht, sondern weil sie die „Öffentlichkeit“ als den „Realisierungsmodus des Menschen nachweisen will“ (Plessner 1975, 346). Die Frage nach dem Absoluten müsse gesellschaftlich offen bleiben, um eine Pluralisierung des „utopischen Standortes“, um eine Pluralisierung der „Exzentrizität seiner [des Menschen: HPK] Lebensform, sein[es] Stehen[s] im Nirgendwo“ (ebd.) und Nirgendwann bejahen (Krüger 1998b) zu können! 
Es müsste sich - und so zeigt es die Geschichte der metaphysischen Spekulation - dem Absoluten gegenüber der gleiche Prozess wiederholen, der zur Transzendierung der Wirklichkeit [in den Monotheismen: HPK] führt: wie die exzentrische Positionsform Vorbedingung dafür ist, dass der Mensch eine Wirklichkeit in Natur, Seele und Mitwelt fasst, so bildet sie zugleich die Bedingung für die Erkenntnis ihrer Haltlosigkeit und Nichtigkeit. (Plessner 1975, 346)

Durch dieses existentielle Paradoxon wird die Frage nach dem Menschen wieder offen und ihm überantwortet, aber nicht in dem Sinne des Entscheidungsdramas für das verselbständigte Bewusstsein.

Statt also die exzentrische Mitte des Lebendigen zu aktualisieren, statt im Spielraum der dualen Aspekte des Lebendigen die hier und jetzt für die Körperleiber angemessene Verschränkung zu finden, statt sich dafür auf die Kommunikation individueller und soziokultureller Urteilskraft einzulassen, wird dem Standpunkt des verselbständigten Bewusstseins alles nichtig und daher einer Transzendenz bedürftig. Im Verhältnis der Unbestimmtheit zum eigenen Körperleib zu stehen - weshalb man an der Kommunikation individueller und soziokultureller Urteilskraft teilnimmt - ist den Philosophien des reflexiv verselbständigten Bewusstseins unerträglich. Sie pendeln in dem von ihnen inszenierten Entscheidungsdrama des Bewusstseins zwischen nihilistischer Desillusionierung und dualistischer Aufrüstung hin und her. Statt den existentialistisch, naturalistisch oder idealistisch schon immer vorentschiedenen Strategien der Selbstermächtigung zu folgen, führt erst die gesellschaftlich plurale Öffentlichkeit in die Öffnung der Frage nach dem Menschen, in das ihm Unbestimmte, Unbedingte und Unendliche hinein, wodurch sie unter den geschichtlich endlichen Bedingungen erneut bestimmbar wird. Demgegenüber zelebrieren die Bewußtseinsphilosophien den Kult der schon immer vorgängigen Entschiedenheit.

Die Philosophische Anthropologie unterscheidet sich mit ihrem dynamischen Differenzierungsversuch der Mitwelt zwischen kulturell brüchiger Gefahr und Geschichtlichkeit wagender Antwort scharf von anderen Konzeptionen. Plessner kritisiert einerseits die Fortschrittsmetaphysiken, die auf eine Akkumulation oder einfache Kumulation von Verkörperungen über die Generationen hinwegsetzen. Diesen Fortschrittsmetaphysiken nach sollen sich das Universalisierbare und Objektivierbare durchsetzen, in Form von Vernunft, von Wirtschafts- und Militärstärke, von erhöhter Lebenserwartung und Bildungsniveau (Plessner 1985d). Die Fortschrittsmetaphysiken knüpfen an ausgewählte Verkörperungs- und Könnensarten an, als ob es deren leibliches Ausdrucks- und Motivationsproblem nicht gäbe, und als ob sich die historische Balance von allein einstellen würde oder durch autoritär-institutionelle Tradierung sichergestellt werden könnte. 
Für Metaphysiken mit solchen Fortschrittskriterien bleibt es immer verwunderlich, wenn sogar Großmächte (vom Römischen Imperium bis zur Sowjetunion), die solche Fortschrittskriterien par excellence zu erfüllen scheinen, nicht nur aus Effizienzgründen, sondern aus Sinn- und Motivationsproblemen zusammenbrechen oder zumindest historisch zurückfallen und im Vergleich zu anderen Mächten peripher werden. In dekadenten Zeiten kommt die Sinnbelegung nicht mehr den verkörperten Bedeutungen nach, in wilden Perioden halten die Verkörperungen nicht mit der Expressionskraft Schritt. Nur in klassischen Epochen scheint sich ein Gleichgewicht herzustellen. Um solche Phänomene längerfristiger Ausgleichsbewegungen in den Blick zu bekommen, muss man nochmals von einem Generationenwechsel durch mehrere Generationenwechsel hindurch und zudem sehen, wie dabei die Differenz zwischen gemeinschaftlichen und gesellschaftlichen Interaktionsarten driftet.

Plessner grenzt das Projekt der Philosophischen Anthropologie andererseits aber auch von dem umgekehrten Fehlschluss ab, für den J.-J. Rousseau und K. Marx wirkungsgeschichtlich stehen (Plessner 1974, 9., 10. u. 12. Kap.). Beide kritisierten die gesellschaftliche Entfremdung, als ob es diese kulturell nicht schon in einem einzigen Generationenwechsel gäbe, und als ob man die anthropologische Norm der Vergegenständlichung und der Aneignung von Gegenständen mit dem Privateigentum abschaffen könnte. Rousseaus Konzeption steht für den ästhetischen Leib einer kleinstädtisch überschaubaren Gemeinschaftlichkeit und für die Individualität ihrer Mitglieder, woran gemessen alles andere als die Entfremdung durch Zivilisation gilt. Marx erweiterte diese Gemeinschaft durch Assoziationen und wissenschaftliche Selbstkontrollen zu einer komplexeren Gemeinschaft von Gemeinschaften. Gleichwohl wollte auch er die Gesellschaft durch ihre Fehlidentifikation mit dem Kapitalismus in Gemeinschaftlichkeit aufheben und mit der kulturellen Not der Entfremdung auch die darauf antwortende Geschichtlichkeit erübrigen. Nach dem Sieg des Kommunismus sollte das Ende der Vorgeschichte der Menschheit eintreten, wobei unklar blieb, ob damit die Geschichtlichkeit des Menschen selber abgeschafft werden müsste.

Für die Philosophische Anthropologie ist das, was Rousseau, oder auf komplexere Weise auch Marx, in ein geschichtsphilosophisches Nacheinander zerlegt haben, eine anthropologische Gleichzeitigkeit im Generationenwechsel, die aus der Not kultureller Entfremdung und deren geschichtlichem Lösungsversuch besteht. Plessners Bejahung der Entfremdung, die er oft und immer wieder mit Hegel - im Sinne der Vergegenständlichung des Geistes - gegen Rousseauisten und Marxisten vorgetragen hat (Plessner 1985b u. 1985f), kann man nur in ihrem anthropologischen Zusammenhang verstehen, der da besagt: Die Ge- 
schichtsbedürftigkeit von Menschen kann schwerlich um Generationen zugunsten der einen großen Lösung vertagt werden und darin gleichzeitig mit einem nicht $\mathrm{zu}$ haltenden Gewissheitsversprechen befriedigt werden. Die Moderne entfaltet sich durch solche ungedeckten, nur geschichtsphilosophisch suggerierten Kredite auf die Zukunft. Sie ist erborgt von dem, was menschenmöglich ist, und haushaltet eben nicht damit.

Die Philosophische Anthropologie fundiert die ständige und erneute Geschichtsbedürftigkeit menschlicher Generationen, indem sie dazu einlädt, das Verhältnis zur eigenen Unbestimmtheit frei und realistisch einzugehen, ohne die notwendigen Möglichkeiten des menschlichen Daseins durch eine es transzendierende Notwendigkeit zu verdecken. Sie ist gerade keine Festschreibung eines historisch invarianten Wesens von Menschen. Demgegenüber erscheint die traditionelle Geschichtsphilosophie gerade nicht als eine Würdigung der geschichtlichen Offenheit von Menschen, sondern als der Versuch, die Menschen auf eine einzige bestimmte Geschichte festzulegen, etwa eine bestimmte Art von Fortschritt oder Rückschritt. Diese Moderne-Projekte führen aber gerade im Namen nur einer einzigen Geschichte in die Geschichtslosigkeit, in das Ende dieser so bestimmten Geschichte, die als das Ende der Geschichte überhaupt ausposaunt wird: die übliche eitle Selbstüberschatzung. ${ }^{7}$

Plessners Philosophische Anthropologie versteht nicht nur alle Kulturen als wertedemokratisch gleich zu stellende, sondern auch die kulturelle und historische Aufgabe aller Generationen. Sie bejaht die Pluralisierung des utopischen Standortes und die Bewährung des Utopisierens in der gesellschaftlichen Öffentlichkeit, wodurch wir uns fragwürdig bleiben. Dies bedeutet dann aber auch für die jeweils Heutigen, derart Geschichte $\mathrm{zu}$ machen, dass die Nachkommen ihrerseits ihr Geschlecht geschichtlich erneuern können. Dieser Verantwortung für die künftigen Generationen, ihre condition humaine, widersprechen Projekte, die sich die Realisierung des Unbedingten anmaßen. Wir stehen hier also vor einem geschichtlichen Problem der begrenzten Selbstermächtigung der Lebenden, der Legitimität ihrer Machtbildung und Machtausführung im Kontext der Erinnerung von Vergangenem und der Antizipation des Zukünftigen. Verantwortung dafür zu übernehmen, dass Kinder und Enkel in der Zukunft einen

7 Odo Marquard kommt in der Geschichte der Philosophie der alten Bundesrepublik das Verdienst zu, Motive der Philosophischen Anthropologie Plessners wiederbelebt zu haben, wenngleich dabei das, was Plessner die „notwendigen Möglichkeiten“ nannte, zeitgeschichtlich in die Provokation durch Negativa geriet, die schon die Titel verraten: „Abschied vom Prinzipiellen“ (Marquard 1981) und „Apologie des Zufälligen“ (Marquard 1986). Siehe zur Krise der nachabsolutistischen Lesart von Geschichtsphilosophie Angehrn 1991. 
Handlungsspielraum haben, schließt die heute weit verbreitete Lebenshaltung „Nach mir die Sintflut“ aus. Auf Plessners Machtphilosophie, die „verantwortungsethisch“, nicht „gesinnungsethisch“ (Weber 1992) angelegt ist, bin ich ausführlich in früheren Büchern eingegangen (Krüger 1999, 6. Kap.; Krüger 2001, 1. Kap.; Krüger 2009a, I. Teil). Auf die geschichtsphilosophische Frage komme ich im dritten Teil des vorliegenden Buches zurück. 